\title{
Understanding the factors that determine workplace coaching effectiveness: a systematic literature review
}

Article

Accepted Version

Bozer, G. and Jones, R. J. (2018) Understanding the factors that determine workplace coaching effectiveness: a systematic literature review. European Journal of Work and Organizational Psychology, 27 (3). pp. 342-361. ISSN 1464-0643 doi: https://doi.org/10.1080/1359432X.2018.1446946 Available at https://centaur.reading.ac.uk/75744/

It is advisable to refer to the publisher's version if you intend to cite from the work. See Guidance on citing.

Published version at: https://doi.org/10.1080/1359432X.2018.1446946

To link to this article DOI: http://dx.doi.org/10.1080/1359432X.2018.1446946

Publisher: Taylor \& Francis

All outputs in CentAUR are protected by Intellectual Property Rights law, including copyright law. Copyright and IPR is retained by the creators or other copyright holders. Terms and conditions for use of this material are defined in the End User Agreement.

www.reading.ac.uk/centaur 
Central Archive at the University of Reading

Reading's research outputs online 


\title{
Understanding the factors that determine workplace coaching effectiveness: A systematic literature review*
}

\begin{abstract}
Meta-analytic results have established that workplace coaching is effective, however, little is known about the determinants of coaching effectiveness. This paper reports an inclusive systematic literature review, covering the quantitative and qualitative research on workplace coaching. We focus on seven promising areas in the current workplace coaching literature that emerged by the synthesis of 117 empirical studies: self-efficacy, coaching motivation, goal orientation, trust, interpersonal attraction, feedback intervention, and supervisory support. The major contribution of our paper is the systematic integration of well-established theoretical constructs in the workplace coaching context and the new insights we provide in the synthesis of these literatures. Based on our review we provide specific recommendations to be addressed in future research, including recommended research methodologies, which we propose will significantly progress the field of workplace coaching theory and practice.
\end{abstract}

Keywords: Coaching; Coaching Effectiveness; Learning and Performance; Professional Development; Systematic Literature Review

\footnotetext{
${ }^{*}$ We wish to thank two anonymous reviewers and the associate editor for their comprehensive and insightful reviews which have helped us to shape and improve our paper.
} 


\section{Workplace coaching effectiveness: An introduction}

Workplace coaching is a one-to-one custom-tailored, learning and development intervention that uses a collaborative, reflective, goal-focused relationship to achieve professional outcomes that are valued by the coachee (Smither, 2011).

Coaching is a learning and development approach that places the learner at the centre of the learning experience. The popularity of coaching appears to be enduring, with an estimated 53,300 professional coach practitioners worldwide (International Coach Federation, 2016). Further, a growing number of organizations are applying coaching in a range of formats and contexts outside of traditional executive coaching (or leadership coaching) where coaching is provided to a client who has managerial authority and responsibility in an organization by an external consultant (International Coach Federation, 2016). Therefore, following Jones, Woods and Guillaume (2016), we use the term workplace coaching as a more inclusive description incorporating coaching provided to all levels of employees by external or internal coaching practitioners who do not have formal supervisory authority over the coachee. The terms executive coaching, leadership coaching, business coaching and workplace coaching are often used interchangeably (e.g., Blackman, Moscardo, \& Gray, 2016; Ely et al., 2010; Theeboom, Beersma, \& Van Vianen, 2014). We use the term 'workplace coaching' as, in our view, it attends to the triadic nature of this developmental intervention (coach, coachee, organization), and reflects the intended outcomes of coaching in an organizational context. Coaching is described as providing the employee with the time, mental space, support and guidance the employee may need to make sense of the information available to them and explore how to apply it most effectively in their unique situation (Day, 2000). In this challenging, volatile business environment, one-to-one coaching provides an adaptable and tailored learning and development solution to facilitate analyzing and comprehension from 
other more instructional forms of training (e.g., Jones, Rafferty, \& Griffin, 2006; Webb, 2006). This context helps to explain why the use of coaching has seen such a sustained increase in recent years.

Despite this growth, there are still a number of unanswered questions related to the determinants of coaching effectiveness, such as what key coachee characteristics are associated with improved coaching outcomes, what factors within the organizational setting promote or hinder coaching success, what factors influence the coach-coachee relationship, and how this links to coaching effectiveness (e.g., De Meuse, Dai, \& Lee, 2009; Feldman \& Lankau, 2005; Jones et al., 2016). Therefore, to address this gap, our paper has two goals. Firstly, to examine critically the theoretical constructs operationalized in past coaching research to provide a deeper understanding of why these factors are important in understanding what determines coaching effectiveness. Secondly, to identify and discuss fundamental questions to be answered, and appropriate research methodologies that can advance workplace coaching research and practice.

To achieve our goals, we conduct a systematic literature review (SLR) in order to understand the theoretical constructs that have been operationalized and tested empirically in the coaching literature. Our SLR differs from previous coaching reviews as firstly, we provide a fully inclusive review incorporating both quantitative and qualitative literatures, as opposed to recent meta-analytic reviews (e.g., De Meuse et al., 2009; Jones et al., 2016; Sonesh et al., 2015; Theeboom et al., 2014) that focus exclusively on quantitative studies and are therefore based on smaller sample sizes ( $k=8,17,26$ and 18 respectively). Secondly, unlike previous literature reviews (e.g., Feldman \& Lankau, 2005; Grant, Passmore, Cavanagh, \& Parker, 2010; Joo, 2005; Passmore \& Fillery-Travis, 2011; Peterson, 2010), we adopt a truly 
systematic methodology by closely following established principles and recommendations for conducting a SLR (see Briner \& Denyer, 2012; Denyer \& Tranfield, 2009; MacPherson \& Jones, 2010; Nolan \& Garavan, 2016). The existing reviews of the coaching literature are positioned as either argument/thematic reviews or expert reviews which do not claim to use explicit rigorous methods (Briner \& Denyer, 2012).

An exception to this is a recent review by Blackman et al. (2016) who sought to provide an overview of the benefits or outcomes of coaching, compare coaching with other techniques, explore factors contributing to effective outcomes, and understand coach credibility. Whilst this review adopts a systematic search methodology, we argue that as Blackman et al.'s (2016) review combines business coaching, supervisory coaching and team coaching studies, the conclusions drawn may be problematic due to the conceptually unique nature of each of these three coaching interventions. Namely, that coaching when provided by a supervisor may impact on the nature of the relationship between the supervisor as coach and the subordinate as coachee due to the pre-existing leader-follower relationship (e.g., Dahling, Taylor, Chau, \& Dwight, 2016; Feldman \& Lankau, 2005; Jones et al., 2016). Likewise, team coaching contains many unique challenges for the coach not present in one-to-one coaching that could influence the validity of conclusions drawn when studies exploring one-to-one coaching are combined with studies exploring team coaching. For example, Jones, Napiersky, Lyubovnikova and Chretien (2017) demonstrate that team coaching requires the coach to demonstrate coaching skills not necessarily required in one-to-one coaching. Such as, simultaneously managing multiple perspectives and facilitating the building of trusting relationships between the numerous coachees present in the same team coaching intervention. By combining studies that examine business coaching, supervisory coaching and team 
coaching, it is impossible to draw conclusions regarding factors such as the impact of the relationship in coaching due to the distinct differences in these different types of coaching.

To achieve our second goal, by synthesizing the literature on coaching and the wider relevant psychological literatures, we formulate a series of future research directions for scholars including recommendations on appropriate research methodology and indicate our view of the priority for our suggestions. In this respect, the diverse nature of the coaching literature means that our paper is likely to be of interest to scholars working in a diverse range of disciplines, such as psychology, HR, management, leadership, and organizational behaviour.

\section{Method of review}

In conducting our comprehensive review, we adopted a systematic approach as outlined in Nolan and Garavan (2016) which builds on the processes advocated by Denyer and Tranfield (2009) and by MacPherson and Jones (2010). A systematic review aims to address the research objective by identifying, critically evaluating, synthesizing and integrating the findings of relevant research (Cooper, 2003). Briner and Denyer (2012) propose that a systematic review should be conducted according to a method that is designed to specifically address the research questions, explicitly state the review method used, be sufficiently detailed so that the review could be replicated, and provide a structured synthesis of the results related to the research question. Figure 1 provides an overview of the SLR process applied in this study.

$$
\text { Insert Figure } 1 \text { about here }
$$

Literature search. In order to identify relevant studies to be included in our review, we searched the following electronic databases: ProQuest, EBSCO, Emerald Full Text, JSTOR 
Business, SAGE Journals Online, Science Direct, Taylor and Francis, Emerald Journals, SpringerLink, Wiley Online Library, and Oxford Journals. We also conducted a search of the first five pages of Google Scholar for each search term, consistent with the procedure suggested by Bowen, Newenham-Kahindi and Herremans (2010) and Arvai, Campbell-Arvai and Steel (2012). The following search terms were used: (coaching) and (effectiveness or outcome or impact or influence or evaluation). Searching the broad term 'coaching' resulted in an automatic return of terms such as 'business coaching', 'executive coaching', and 'coaching research'; thus, ensuring that our search was fully inclusive. In addition to this electronic databases search, frequent contributors to coaching research were contacted directly by e-mail to ensure that any unpublished data or work in progress were included in the review. For each of these frequent contributors, we also reviewed their ResearchGate and Institutional profile pages in order to identify any missing studies. We posted an announcement on the Academy of Management OB and Leadership list-servs requesting any unpublished data or work in progress. Finally, we manually reviewed the reference lists of all the other reviews and metaanalyses cited in this paper. The literature search was conducted between September 2015 and October 2017.

Inclusion criteria. To be included in our review, studies had to meet three criteria. First, the study had to examine coaching effectiveness within an organizational setting (i.e., studies in which coaching was provided with the objective of generating workplace outcomes such as performance or skills enhancement). Consequently, studies that measured the impact of coaching on non-work outcomes (such as sport or health) were excluded. Secondly, studies were included if they adequately described the coaching activity (i.e., one-to-one development intervention based on a coach-coachee relationship). Therefore, studies that measured the impact of team coaching were excluded. Studies that measured the impact of coaching 
provided by a supervisor (i.e., managerial/supervisory coaching) were also excluded. As detailed above, it has previously been argued (e.g., Dahling et al., 2016; Feldman \& Lankau, 2005; Jones et al., 2016) that the coaching relationship is distinct from formalized organizational performance management relationships (e.g., supervisor-subordinate). Therefore, it would be inappropriate to group studies that examine the impact of supervisory coaching with non-supervisory coaching in a review such as ours. Moreover, supervisory coaching is usually informal and often difficult to distinguish from mentoring (Doorewaard \& Meihuizen, 2000). Finally, studies had to have been published in English. We approached the authors of studies that were missing critical information that was essential to: (a) determine the study fit within our inclusion criteria (i.e. description of the coaching intervention), and (b) identify the determinants or outcomes of the coaching intervention. In cases where these data could not be retrieved the study was excluded from our review.

Following Adams, Smart, and Sigismund Huff's (2016) recommendations, we also include $1^{\text {st }}$ tier 'grey literature' (e.g., conference proceedings, dissertations and theses) that are characterized with significant retrievability and credibility. Incorporating articles published in non-ranked peer-reviewed coaching journals coupled with $1^{\text {st }}$ tier 'grey literature' is in line with the fitness for purpose inclusion principle (e.g., Briner, Denyer \& Rousseau, 2009; Gough, 2007; Nutley, Powell \& Davies, 2013). This reflects our desire to increase the relevance and impact of our review to scholars and practitioners alike by providing a sufficiently rich detailed literature review that enhances our understanding of coaching as a complex intervention. In order to achieve a balance between fitness for purpose inclusion and replicability of our search (Adams et al., 2016), we restricted our search of the grey literature to those sources retrievable from the well-established academic databases. 
As this systematic review was designed to be as inclusive as possible, studies were not excluded based on research design or restricted based on publication date as was the case in recent coaching meta-analyses (e.g., Jones et al., 2016; Sonesh et al., 2015; Theeboom et al., 2014). Therefore, both qualitative and quantitative data were included covering a range of between and within designs, such as case studies, cross-sectional studies, and quasiexperimental studies. As the primary objective of our study was to comprehensively review the theoretical constructs operationalized in past coaching research, we adopted the approach of other authors in recent SLRs whereby the results from quantitative and qualitative studies were combined and considered together (e.g., Janssen, van Vuuren, \& de Jong, 2015; Nolan \& Garavan, 2016). Denyer and Tranfield (2009) state that through the synthesis of findings, a systematic review should develop knowledge that is not apparent from reading the individual studies in isolation. We believe that by combining the quantitative and qualitative coaching research with the wider theoretical literatures we are able to successfully achieve this aim.

Data set. Our search identified 389,522 studies, of which 117 were considered to be relevant following the application of our inclusion criteria. A PRISMA diagram introduced by Moher, Liberati, Tetzlaff, and Altman (2009) to illustrate the flow of information through the four phases of the systematic review is displayed in Figure 2. All studies included in the literature review are summarized in the appendix (available online) and listed in the references marked with asterisks $(*)$.

Insert Figure 2 about here 
Description of variables. The coding of studies was as detailed as possible to provide a comprehensive review of the existing coaching literature. All eligible studies were coded on the antecedents, mediators, and moderators examined, plus a number of specific variables in order to obtain an overview of the research methodology including: source of study, publication year, research design (i.e. within or between subjects), sample size, sampling strategy (e.g., random, convenience) and measurement strategy (e.g., pre \& post-test, crosssectional). We also adopted the theoretical framework of coaching outcomes developed by Jones et al. (2016) as a mechanism by which to code the outcomes measured in the studies identified in our review. Therefore, consistent with this framework we coded outcomes as affective (e.g., self-awareness; Bozer, Sarros, \& Santora, 2014), cognitive (e.g., solutionfocused thinking; Grant, 2014), skill-based (e.g., safety-oriented communication; Kines et al., 2010) or results (e.g., sickness absence; Duijts, Kant, van den Brandt \& Swaen, 2008). Of the studies in our review, 93 explored affective outcomes, 13 explored cognitive outcomes, 57 explored skill-based outcomes, and 17 explored results outcomes (a number of studies explored outcomes across multiple categories). In Table 1 we provide a summary of the types of outcomes explored when split by the seven theoretical constructs explored in our review.

\section{Insert Table 1 about here}

Coding accuracy and interrater agreement. The coding protocol was developed jointly by both authors and both authors independently coded data from each study that met the inclusion criteria. In order to confirm interrater agreement, our approach mirrored that of Wang and Chugh (2014). Accordingly, all studies were cross-checked independently by both authors and any discrepancies discussed until an agreement was reached. 
Assessment of study quality. An essential component of the systematic review methodology is an assessment of the study quality for each of the studies included in the review, and an overall assessment of the implications of this assessment (Briner \& Denyer, 2012). In the field of medicine, from which the method of systematic review derives, the GRADE approach is accepted as the appropriate method of conducting such assessments (Guyatt et al., 2008). However, the GRADE approach assumes that all primary studies within the review are conducted from a quantitative perspective and, furthermore, they prioritise randomised controlled trials over other research methodologies. Briner and Denyer (2012) highlight that an essential component of conducting an assessment of the quality of empirical articles within a review is to consider the relative quality based on the research questions in-hand. Therefore, when cause and effect is the research question to be addressed, a research design where the assumptions of causality are met (such as the RCT) would naturally be assessed as higher quality than a research design where causality cannot be inferred (such as a cross-sectional study). As the review in-hand is focused on the theoretical constructs operationalized in workplace coaching research, and workplace coaching can be classified as a relatively nascent field of study, only a small minority of studies utilized the RCT design. Our review is comprehensive in nature and, therefore, seeks to include both exploratory and cause-andeffect empirical studies. As such, the studies in our review adopt both qualitative and quantitative research design. Having a theoretical framework underpinning each constructs at the outset is essential for applying appropriate data collection methods, choosing analytic approaches, and ultimately, drawing conclusions (Walsh \& Downe, 2006). In our review, a reliance on theory is fundamental to address the pressing question why coaching is effective, and thus enhance the credibility of the coaching field. Consequently, in order to assess the relative quality of the individual studies within our review, rather than simply ranking studies of a higher quality when a RCT design was adopted, we provide an assessment of whether the 
primary study describes an underlying theoretical construct. We award a score of either 1 for yes a theoretical construct is present or 0 for no a theoretical construct is not present.

In order to provide a further assessment of study quality, we adopt the directness and consistency ratings which originate from the GRADE approach (Guyatt et al., 2011a, 2011b). In the context of medical research, directness refers to "research that directly compares the interventions in which we are interested delivered to the populations in which we are interested and measures the outcomes important to patients" (Guyatt et al., 2011a, p. 1304). In the context of our review, the population is already consistent as this criterion is covered in our inclusion criteria (i.e. population must be working adults). However, there is some degree of variation in terms of directness of intervention and outcomes.

Regarding directness of coaching intervention, criteria for inclusion in our review specifies that studies must utilize one-to-one coaching within the workplace provided by an internal or external coach who does not have a formal authority over the coachee (e.g., not the supervisor). However, a number of the studies in our review reported the outcomes of coaching applied in conjunction with additional interventions, such as leadership development (e.g., Bowles, Cunningham, De La Rosa \& Picano, 2007; Grant, Curtayne \& Burton, 2009; Nieminen, Smerek, Kotrba \& Denison, 2013), managerial learning and training workshop (e.g., Baron \& Morin, 2010; Olivero, Bane \& Kopelman, 1997; Taie, 2011), multi-source feedback (e.g., Kochanowski, Seifert \& Yukl, 2010; Luthans \& Peterson, 2003; Thach, 2002), and team activities (e.g., McGuffin \& Obonyo, 2010; Ratiu, David \& Baban, 2015; Spurk, Kauffield, Barthauer \& Heinemann, 2015). In the majority of these studies the accompanying activities were embedded in the coaching as part of an organizational development initiative 
and, therefore, the coaching effects could not be isolated from the other interventions. In the context of our review, indirectness in terms of the intervention means that we are unable to isolate the unique coaching effects from the overall development. Consequently, there is a possibility of confounding variables and threats to internal validity of workplace coaching effectiveness (Clarke, 2003). As such, we also rate the studies in our review for directness of intervention in that studies were awarded a rating of 1 if the intervention effects could be attributed to a sole intervention, and a 0 if the effects could not be isolated to a single intervention (possibly because the intervention was part of a multi-modal intervention).

Regarding directness of coaching outcomes, our review has identified that the primary studies in our review utilize a vast range of quantitative and qualitative outcomes from a wide variety of sources. In the context of medical research, the GRADE criteria refer to the use of substitute or surrogate endpoints in place of the outcome of interest as one component of indirectness. Translating this to the current review, we argue that we are interested in obtaining an unbiased understanding of the influence of theoretical factors on coaching outcomes. Accordingly, when these outcomes are assessed by either objective means, such as sales performance, or by ratings from external sources of coachee's performance, such as supervisor or peers, we can be more confident that a demonstrable change following coaching has been observed and, as such, measurements of this type would be classified as having high directness and consequently awarded a score of 1.0.

Outcome data collected from the coachee (i.e. self-report data), we propose, could be ranked as moderate and assigned a score of 0.5 as whilst the coachee themselves may be best placed to identify change in outcomes at certain levels, such as affective outcomes, it could also be 
argued that it is difficult to disassociate the coachee's perception of the impact of coaching from factors such as the placebo effect. Another possible risk of bias may occur when coachees perceive that it is in their personal interest to report positively on the coaching outcomes after they have devoted time and effort engaging in coaching, and their organizations have sponsored and coordinated the coaching (De Meuse et al., 2009).

Finally, primary studies that utilize outcomes from the coaches' perspective can be classified as a surrogate endpoint (Guyatt et al., 2011a, 2011b) and, therefore, these studies should be classified as low directness and assigned a score of 0.0 for this element. This is because we would suggest that data collected from the coach has a low level of directness regarding demonstrable change following coaching as the coach is potentially less likely or able to offer a fully objective assessment of outcomes following coaching that they have provided. Further, our review included only coaches who did not have a formal supervisory authority over their coachees, therefore, there might be job-related measures, such as skill-based and performance outcomes, that are not suitable to be assessed by the coaches. Another potential bias in the coaches' effectiveness ratings might derive from their self-interest to demonstrate their professional success as reflected by positive coaching outcomes.

The final criterion which we used to assess study quality was applied at the theme level rather than for individual studies and this was consistency. Consistency in the context of the GRADE approach refers to "inconsistency in the magnitude of effect" (Guyatt et al., 2011b, p. 1294). The GRADE guidelines recommend that consistency is marked down when the inconsistency across findings is large and unexplained. Whilst the GRADE approach focuses on a statistical assessment of consistency, we adopt a similar approach to Rees et al. (2016) 
and assess consistency across the seven themes identified in our review. Accordingly, for a theme which demonstrates relatively high heterogeneity of findings, we rate consistency as low and assign a grade of 0 whereas for themes that demonstrate relatively high homogeneity of findings we rate consistency as high and assign a grade of 1 .

Table 2 provides an overview of the seven theoretical constructs identified in our review, the mean quality rating was the average taken from the scores awarded on theoretical framework, consistency of evidence, directness of intervention, and directness of outcome. The individual study assessment ratings for quality (inclusion of a theoretical framework), directness of outcome and intervention can be found in the table in the appendix available online.

Insert Table 2 about here

Identification of theoretical constructs. The next stage in a systematic literature review is the synthesis of the primary papers and the identification of themes around which the presentation of the review will be provided. In contrast to quantitative meta-analysis, Wolf (1986) argues that qualitative synthesis is not about averaging or reducing findings to a common metric, instead the focus is on enlarging the interpretive possibilities of findings and constructing larger narratives or general theories. Additionally, Thomas and Harden (2008) state that this stage of a qualitative synthesis is the most difficult to describe and is, potentially, the most controversial, since it is dependent on the reviewers' judgement and insights. In order to identify the themes around which our discussion is structured, we focused on the theoretical constructs examined in the extant literature and we inductively identify the theoretical constructs that have been most frequently operationalized in the studies in our review. To 
identify these theoretical constructs, both authors independently reviewed each of the studies identified in our review and coded the studies based on the theoretical constructs each study operationalized. Following this independent coding, each author independently identified the most frequently operationalized constructs. Both authors then discussed their independently created list of constructs until an agreement was achieved in relation to which constructs to discuss in the paper. In agreeing on constructs, the authors sought to achieve a balance between including the most frequently operationalized theoretical constructs and the ability to discuss each construct in sufficient detail within the paper. Consequently, it was not possible to explore in detail all of the constructs identified in the primary studies, a point which we will return to in the discussion of limitations in our conclusion. This process resulted in identifying seven theoretical constructs: self-efficacy, coaching motivation, goal orientation, trust, interpersonal attraction, feedback intervention, and supervisory support. We discuss these theoretical constructs in the subsequent sections of our paper. We structure the results and discussion as follows: first, we introduce and discuss the relevant theoretical construct. Second, we summarize the findings from the studies in our review in relation to this construct. Next, we extend these findings by integrating the general discussion of theory with the coaching research in order to explain how the theoretical construct adds to our understanding of workplace coaching. Finally, we conclude each section with recommendations for future research including suggested methodologies and our view on the priority of each research category.

\section{Results and Discussion}

Self-efficacy. 
Social cognitive theory highlights self-efficacy as a central mechanism with a wide explanatory power on diverse phenomena (Bandura, 1982). Research on self-efficacy has focused on how individuals' self-judgments of efficacy affect either their acquisition of knowledge and skills or execution of action (Gist \& Mitchell, 1992). Research indicates that individuals higher in self-efficacy have strong beliefs in their task-related capabilities and set more challenging goals than those with lower self-efficacy (Bandura, 1986). Occupational self-efficacy has been shown to directly relate to job satisfaction, greater attention and efforts to overcome failure and obstacles and, ultimately, to work-related performance (Judge \& Bono, 2001; Stajkovic \& Luthans, 1998). Self-efficacy has emerged as a powerful predictor of motivation, engagement behaviour and performance in the realm of learning and development (e.g., Choi, Price \& Vinokur, 2003; Tannenbaum, Mathieu, Salas \& CannonBowers, 1991). High perceived self-efficacy as a learner is associated with investment of cognitive efforts and superior learning. In the wider context of training, self-efficacy as a psychological trainee characteristic can be regarded as an independent variable, a process variable, or a desirable outcome (e.g., Colquitt, LePine \& Noe, 2000; Quiñones, 1995).

Studies in our review investigated coachee self-efficacy as both an independent variable and an outcome of coaching with the quality of evidence rated as relatively high (see Table 2). Coachee self-efficacy has been found to be an important antecedent of affective coaching outcomes as reflected in perceived coaching effectiveness (de Haan, Duckworth, Birch \& Jones, 2013; de Haan, Grant, Burger \& Erikkson, 2016), and improved coachee selfawareness and responsibility (Gegner, 1997). Additionally, coachee self-efficacy has been found to be an antecedent of skill-based outcomes as reflected in improved self-reported job performance (Bozer, Sarros \& Santora, 2013), and transformational leadership (Mackie, 2015a). Coachee self-efficacy has also been conceptualised as an affective coaching outcome 
(e.g., Baron \& Morin, 2009, 2010; Baron, Morin \& Morin, 2011; Dingman, 2004; Finn, Mason \& Bradley, 2007; Grant, 2014; Grant, Studholme, Verma, Kirkwood, Paton \& O’Connor, 2017; Ladegard \& Gjerde, 2014; Libri \& Kemp, 2006; Moen \& Allgood, 2009; Moen \& Federici, 2012a; Moen \& Skaalvik, 2009; Tooth, Nielsen \& Armstrong, 2013).

These findings in the coaching literature, supported by the general self-efficacy research, position coachee self-efficacy as a key psychological variable in coaching. Given the centrality of behavioural and cognitive processes in coaching, such as feedback information, planning and goal-setting, the links demonstrated by Bandura (1986) between self-efficacy, challenging goals, greater application of attention and efforts in the face of challenges to goals (Judge \& Bono, 2001; Stajkovic \& Luthans, 1998) explain why high pre-coaching selfefficacy is an antecedent to coaching outcomes. Higher self-efficacy indicates that the coachee is more likely to set more challenging goals, has a greater belief in his or her ability to achieve the goals, and will experience sustained internal motivation, focus, and persistence in the face of obstacles in the pursuit of these goals. According to Bandura (1982), selfefficacy is malleable and can be increased via four processes including enactive mastery, successful model replication after overcoming difficulty, verbal persuasion, and emotional arousal. The coaching literature reviewed suggests that these four processes are integral components of coaching. For example, an aim of coaching is to build coachees' selfawareness and sense of responsibility for change in order to encourage learning, goal achievement and, ultimately, performance improvement (Whitmore, 2002). An underlying assumption of this premise is that all individuals have the ability to achieve their goals (Gallwey, 2002). By questioning faulty assumptions, re-examining the reality based on the evidence, and promoting insight into personal strengths, coachees' self-efficacy in relation to their goals is indirectly targeted, with the research findings that position post-coaching self- 
efficacy as an outcome of coaching, supporting this premise (e.g., Baron \& Morin, 2010; Ladegard \& Gjerde, 2014; Moen \& Allgood, 2009).

Future research in relation to self-efficacy and coaching should further understand the importance of task versus generalized self-efficacy on coaching outcomes. The studies in our review conceptualised self-efficacy as a generalized global personality construct (Schwarzer, 1994; Shelton, 1990). However, self-efficacy can also be considered as a domain-specific variable (e.g., Schwarzer \& Fuchs, 1995) and as a task-specific variable to predict circumscribed behaviour (Bandura, 1977; Pajares, 1996). In the coaching context, when coachees are unfamiliar with the specific tasks and challenges that they will face during their engagement in coaching, coachees' domain specific self-efficacy may provide greater explanation and predictive value of behaviours and outcomes than their general self-efficacy. Accordingly, future research should understand the influence of global self-efficacy beliefs (i.e. general belief in ability to generally develop knowledge, skills and abilities to achieve outcomes) compared to domain-specific self-efficacy (i.e. belief in ability to develop the knowledge, skills and abilities necessary from coaching to achieve outcomes) and taskspecific self-efficacy (i.e. specific belief in ability to develop the knowledge, skills and abilities necessary from coaching to achieve task level outcomes).

A limitation of the existing research into self-efficacy and coaching effectiveness is that selfefficacy has generally been measured at one time point only. If future research is to explore domain or task-specific self-efficacy, then alternative research methodologies will need to be utilized. One such appropriate method in this context would be the use of diary studies. Previous diary studies have demonstrated that employees' day-level self-efficacy had a positive effect on performance as reflected in job crafting behaviours (Tims, Bakker, \& 
Derks, 2014), work engagement (Xanthopoulou, Bakker, Demerouti, \& Schaufeli, 2009), and job performance (Xanthopoulou, Bakker, Heuven, Demerouti, \& Schaufeli, 2008), at the intra-individual level of analyses. Coaching effectiveness research could benefit from tracking the impact of changes in domain or task-specific self-efficacy beliefs and subsequent outcomes from coaching. Particularly, this domain would benefit from research utilizing outcomes as assessed by third-party or objective sources and with particular focus on outcomes other than those at the affective level given the heavy reliance in the existing literature in this respect (see Tables 2 and 3 for an overview). Given the very clear links in the literature between self-efficacy, performance and training outcomes, we would mark the future research in this category as an urgent priority.

\section{Coaching motivation.}

Salas and Cannon-Bowers (2001) suggest that training motivation is an important antecedent to successful training. They describe training motivation as the "direction, effort, intensity, and persistence that trainees apply to learning-oriented activities before, during, and after training" (p. 479). Research has found that trainees' motivation to learn and attend training has an effect on the subsequent skills acquisition, retention and willingness to apply the newly acquired knowledge, skills and abilities on the job (e.g., Martocchio \& Webster, 1992; Quinones, 1995). Colquitt, LePine and Noe (2000) suggest that training motivation is multifaceted and influenced by a set of individual (e.g., cognitive ability, self-efficacy, anxiety, age, conscientiousness), and situational characteristics (e.g., climate, support).

Studies in our review conceptualize coaching motivation in a variety of ways. For example, Audet and Couteret (2012) refer to coachees' motivation as a receptivity to coaching and 
commitment to the coaching relationship; Bozer et al. (2013) adopt Colquitt et al's (2000) definition of pre-training motivation in the context of coaching and refer to the direction, intensity and persistence of learning directed behaviour in training contexts and MacKie (2015a) refers to the developmental readiness of the coachee. Whilst the coaching studies in our review that explored these concepts utilize a range of terminology, in our view, all of these coaching motivation concepts can be adequately classified according to the definition of training motivation provided by Salas and Cannon-Bowers (2001). The majority of studies in our review explored coaching motivation qualitatively, with findings indicating that coaching motivation was an antecedent to coaching outcomes when assessed from the perspective of the coachee (Bush, 2004; Hill, 2010; Rekalde, Landeta \& Albizu, 2015; Salomaa, 2015); the coach (Audet \& Couteret, 2012; Hill, 2010; Kappenberg, 2008; Rekalde et al., 2015; Salomaa, 2015); and HR professionals (Rekalde et al., 2015; Salomaa, 2015). Fewer studies utilized quantitative analysis to examine the impact of coaching motivation on coaching outcomes. For example, MacKie (2015a) found that coaching readiness was a significant predictor of skill-based outcomes as reflected in improved transformational leadership behaviour (as rated by self and others such as line manager, peers and subordinates) after coaching for sample one, although the findings for sample two were not significant. In a sample of 89 coach-coachee dyads, Sonesh et al. (2015) found that there was no significant relationship between coachee motivation, goal attainment and coachee insight. Whereas Bozer et al. (2013) found that coaching motivation was a significant moderator between coachee learning goal orientation and coaching effectiveness. Our overall rating of the quality of evidence in relation to coaching motivation and coaching effectiveness is relatively high (see Table 2). 
The implication of the findings that position coaching motivation as an important antecedent of coaching outcomes is consistent with the extant training motivation literature (e.g., Martocchio \& Webster, 1992; Quinones, 1995). As with training, if coachees are not motivated to invest effort and persistence towards change in attitude, skills and performance following coaching, then the coaching is unlikely to have the desired impact. However, positioning coaching motivation purely as an antecedent is perhaps too simplistic. Salas and Cannon-Bowers (2001) suggest that training motivation applies before, during, and after training. The extant literature examining coaching motivation has focused on pre-coaching motivation. It may also be important to consider coaching motivation as an affective outcome of coaching. For example, popular definitions of coaching suggest that coaching enhances coachee's personal growth by providing the tools, skills and opportunities he or she needs to develop themselves and become more effective (Bono, Purvanova, Towler \& Peterson, 2009; Kilburg, 1996; McCauley \& Hezlett, 2002; Peterson \& Hicks, 1996; Smither, 2011; Witherspoon \& White, 1996). The focus on continued self-development, even after the coaching intervention has concluded, highlights the emphasis in coaching on encouraging the coachee to take responsibility for their own professional development and have the sustained ability to apply the tools, skills, and opportunities addressed in coaching to new situations that arise post-coaching. This would only be possible if the coachee was to continue with a high level of coaching motivation after the coaching has completed; that is, a high level of "direction, effort, intensity, and persistence that trainees apply to learning-oriented activities" (Salas \& Cannon-Bowers, 2001, p. 479). In order to explore this, future coaching research should more consistently adopt longitudinal methodologies.

Only a few studies in our review explored the impact of coaching over an extended period of time at multiple time points. Furthermore, as coaching motivation is generally treated as an 
independent variable, even when multiple post-coaching measures are collected, coaching motivation is not measured after coaching has completed. Collecting longitudinal data in relation to coaching motivation would increase our understanding of the impact and sustainability of this variable across various stages of the coaching intervention. The concept of coaching motivation is also important to consider in the context of a range of other theoretical constructs explored here, for example, the related topics of goal orientation (see next section) and self-efficacy. The coaching literature has yet to adequately examine how coaching motivation is related to, or the interaction between, the coachees' goal orientation or self-efficacy and the impact of these relationships on coaching outcomes. For example, only one study identified in our review (Bozer et al., 2013) tested the moderating effect of coaching motivation on the impact of coachees' learning goal orientation and coaching outcomes. Bozer et al.'s findings lend support to the idea that the theoretical constructs explored in our paper have a complex and interlinking effect on coaching outcomes. Thus, more research is needed to fully understand both, the explanatory and predictive power of the interaction effects of coaching motivation, self-efficacy, and learning goal orientation that might either promote or hinder coaching effectiveness. Given the proximal nature of coaching motivation to the coachee and the assumed importance of this variable on outcomes based on the training literatures, we suggest that future research within this category is of a high priority.

\section{Goal orientation.}

Using social cognitive theory as a framework, researchers (e.g., Brett \& VandeWalle, 1999;

Dweck, 1986) have presented a mental model of motivational processes that influence individuals' interpretation and response to achievement situations. Dweck's (1986) theory of 
goal orientation suggests two different goal orientations that individuals pursue in achievement settings, namely, performance goal orientation and learning goal orientation. Individuals who are learning goal oriented believe that their abilities are malleable, and therefore generally focus on ways to increase their learning and/or task competence, acquire and develop new knowledge and skills, seek challenges, and persist to attain desired results in the case of failure. In contrast, individuals who are performance goal oriented hold the belief that ability is fixed, therefore, they focus on the outcomes of their performance and do not strive to learn but rather to demonstrate their current ability (e.g., Button, Mathieu, \& Zajac, 1996; Dweck \& Leggett, 1988). Although some researchers perceive goal orientation as a single two-ended construct, with learning orientation at one extreme and performance orientation at the other (Dweck \& Leggett, 1988), more recent research (e.g., Elliot \& McGregor, 2001; VandeWalle, 1997 suggests that the same individual might have high levels of both learning orientation and performance orientation.

In a training and learning context, learning goal orientation is considered to be a major individual motivational factor that influences the allocation of effort to learn, perform, and facilitates training transfer (Fisher \& Ford, 1998; Kafner, Ackerman, Murtha, Dugdale \& Nelson, 1994). That is trainees with a learning goal orientation are more likely to make sustained efforts (Hertenstein 2001), seek feedback (VandeWalle and Cummings, 1997), possess high self-efficacy (Kozlowski et al., 2001), and have greater performance in training interventions (Bell \& Kozlowski, 2002). Studies in our review investigated coachee goal orientation as antecedent of coaching effectiveness and, overall, the studies within this domain can be rated as high quality (see Table 2). Specifically, coachee learning goal orientation was positively related to skill-based outcomes as reflected in improved selfreported job performance (Bozer et al., 2013; Jones, 2015) and in self-reported professional 
development focus (Scriffignano, 2011). The positive link between learning goal orientation and coaching outcomes is consistent with the underlying assumption in coaching that individuals have the ability to change and achieve their goals (Ennis, Otto, Goodman \& Stern, 2012). A learning goal orientation indicates that a coachee is more likely to hold the belief that they are able to change, this belief will then influence the individual's focus on their goal, likelihood to seek challenging goals and persistence towards desired results, even in the face of failure.

Future research should explore whether conceptualising goal orientation in alternative frameworks such as the four-factor framework proposed by Elliot and McGregor (2001) offer additional insights into understanding the importance of goal orientation and coaching outcomes. Also, given the importance in coaching in encouraging the coachee to take responsibility for their own professional development and to have the sustained ability to apply the learning gained via coaching to new situations after the coaching intervention has concluded, future research could also position goal orientation as an affective outcome of coaching. The studies in our review conceptualised goal orientation as a stable, trait like, individual-difference characteristic. However, given the debate in the literature regarding the conceptualisation of goal orientation as a trait or state (Colquitt \& Simmering, 1998; Payne, Youngcourt \& Beaubien, 2007), it follows that if it is assumed that goal orientation is a state, then coaching would be an ideal intervention through which to foster a learning goal orientation. Accordingly, longitudinal methodologies measuring goal orientation at multiple time points would be appropriate for future coaching motivation research. As with selfefficacy theory, given the extensive evidence to indicate the importance of goal orientation in relation to performance and training outcomes, we suggest that research in this category is an urgent priority. 
Trust.

The significance of trust in relation to the leader-follower relationship has received extensive research attention (e.g., Dirks, 2000; Dirks \& Ferrin, 2000), and has also been explored in the context of mentoring relationships (e.g., Erdem \& Aytemur, 2008; Wang, Tomlinson \& Noe, 2010). Rousseau, Sitkin, Burt, and Camerer (1998) define trust as "a psychological state comprising the intention to accept vulnerability based upon positive expectations of the intentions or behaviour of another" (p. 395). Dirks and Ferrin (2000) sought to provide a theoretical framework which could be utilized to make sense of the alternative explanations available in relation to leadership and trust. Dirks and Ferrin suggest that there are two opposing theoretical perspectives to viewing trust in leadership. The first perspective focuses on the nature of the leader-follower relationship, with trust in leadership described as operating according to a social exchange process (e.g., Konovsky \& Pugh, 1994; Whitener, Brodt, Korsgaard \& Werner, 1998). Followers see the relationship with their leader as more than the standard economic contract, such that the parties operate on the basis of trust, goodwill, and the perception of mutual obligations (Blau, 1964). Researchers have used this perspective in describing how trust in leader-follower relationships elicits citizenship behaviours (e.g., Konovsky \& Pugh, 1994). The second perspective focuses on the leader's character and how it influences a follower's sense of vulnerability in a hierarchical relationship (e.g., Mayer, Davis \& Shoorman, 1995). Consequently, trust-related concerns about a leader's character are important because the leader may have authority to make decisions that have a significant impact on a follower and the follower's ability to achieve his or her goals. Examples of research using this perspective include models of trust based on characteristics of the trustee (Mayer et al., 1995), research on perceptions of supervisor 
characteristics (e.g., Cunningham \& MacGregor, 2000), and research on some forms of leader behaviour (Jones, James \& Bruni, 1975).

We propose that the character perspective to understanding leader-follower trust is most relevant to understanding coach-coachee trust. For example, in a coaching relationship, the coachee needs to believe that they can trust their coach, so that they can allow themselves to be vulnerable and transparent (to explore their weakness and limitations) as, via the coaching intervention, the coach will have an impact on the coachees' ability to achieve his or her goals. In the leadership literature, this character perspective to trust focuses on how the perceptions of the leader's character affect a follower's vulnerability in a hierarchical relationship. Mayer et al. (1995) propose a model suggesting that when followers believe their leaders have integrity, capability, or benevolence, they will be more comfortable engaging in behaviours that put them at risk (e.g., sharing sensitive information). In the context of mentoring, Mayer, Davis and Schoorman $(1995,1999)$ suggest that this psychological safety experienced by the protégé can be described as a willingness to engage in risk taking actions and being vulnerable to the action of the mentor.

The concept of trust is well documented in the coaching studies in our review. Generally, these studies have adopted the character perspective to understand coach-coachee trust, although the majority of these studies have implicitly applied this theoretical perspective, this is reflected in the lower rating of quality of theoretical underpinning as shown in Table 2. For example, Boyce, Jackson and Neal (2010) explored the coachees' level of trust in the coach and the coaches' perceptions of the coachees' honesty and candidness in the coaching conversations. Boyce et al. found that coachees' ratings of trust were a significant predictor of affective outcomes in the format of coachees' ratings of satisfaction/utility and success of 
their coaching programme. However, coachee perceptions of trust were not a significant predictor at the skill-based outcome level for self-reported improvements in leadership performance following coaching. From the coaches' perspective, perceptions of the coachees' honesty and candidness were significant predictors of affective outcomes in the format of the coaches' perceptions of the success of the coaching intervention. However, in a sample of 172 coachees, Gan and Chong (2015) found that trust was not a significant predictor of perceived coaching effectiveness. Qualitative studies in our review highlight the importance of the coachees' perceptions of trust (Alvey \& Barclay, 2007; Bush, 2004; Gyllensten \& Palmer, 2006, 2007; Hill, 2010; Jowett, Kanakoglou \& Passmore, 2012; Kappenberg, 2008; Rekalde et al., 2015; Salomaa, 2015). Particularly, these studies highlighted the importance the coachees placed on trusting that the coach would maintain their confidentiality, therefore supporting the proposition that when trust is present, the coachee is more likely to engage in vulnerability behaviours such as sharing sensitive information.

Future research should address the issue of understanding the theoretical character perspective of trust more explicitly in the context of coaching. For example, what characteristics in particular are more likely to lead to the coachee developing strong perceptions of trust in their coach? When a high level of trust has been established, what is the impact on behaviours within the coaching conversations; for example, is an increase in vulnerable behaviours (such as sharing sensitive information) observed and if so, what impact does this have on the content of discussion in the coaching conversation? What is the nature of the interaction between trust in the coaching relationship and the other constructs discussed in this review? For example, it seems likely that high levels of trust would also foster high levels of engagement with the coaching intervention as the coachee perceives that the coach will have the ability to help them through coaching to achieve their goals. Therefore, high perceptions 
of trust may indicate higher levels of coaching motivation. Higher levels of interpersonal attraction (see next section) at the outset of the coaching relationship may accelerate the development of the coachees' trust in the coach, therefore accelerating the rate at which positive outcomes from coaching are observed. Further, consistent with the role of trust in mentoring relationship (Eby et al., 2013), it is proposed that coachees with high levels of trust in the coach will be more open and receptive to feedback provided by the coach during coaching and this is likely to increase affective outcomes of coaching (e.g., self-awareness, self-efficacy). To examine these questions, the methodology by which coaching is examined will also need to develop to enable coach-coachee interaction analysis. For example, to understand the impact of trust on behaviours during the coaching conversation fully, observational studies of actual coaching conversations (e.g., videotaped coaching dyads) will need to be completed, rather than the heavy reliance of self-reported questionnaire data of coaching impact that is characteristic of the existing coaching studies. This recommendation would also address the lower rating of directness of outcome in this domain shown in Table 2 by complimenting coach ratings of outcomes with external source ratings. The concept of trust has been operationalized frequently in a range of studies identified in our review, however we suggest that future research with an increased theoretical focus as suggested here is a high priority.

\section{Interpersonal attraction.}

Interpersonal attraction as a social integration concept is well documented in the psychology, management and sociology literature and has been investigated at both the dyad and group levels of analysis (e.g., Hogg \& Turner, 1985; Tsui \& O'Reilly, 1989). Within this concept, similarity paradigm or homophily has been highlighted as a mechanism to explain why 
human beings have a natural tendency to identify and attract with individuals perceived similar to themselves. Similarity paradigm or homophily refers to the preference for interaction with similar others based on actual or perceived similarity on given personal attributes (e.g., demographic, ascribed and attitudinal) (e.g., Byrne, 1997; Harrison, Price \& Bell, 1998). Similarity of personal characteristics implies common values, perspectives and interests and therefore fosters relationships of mutual trust and effective interpersonal communication. Research on similarity paradigm in related developmental fields (e.g., learning, mentoring) indicates benefits in interpersonal comfort, process engagement and, ultimately, successful outcomes (e.g., Armstrong, Allinson, \& Hayes, 2002; Lyons \& Perrewé, 2014; Mitchell, Eby, \& Ragins, 2015; Varela, Cater, \& Michel, 2011).

It is commonly believed that a high level of interpersonal attraction, otherwise described as a good coach-coachee match or coach-coachee compatibility, is essential for an effective coaching relationship, which is fundamental for successful coaching outcomes (e.g., de Haan et al., 2013). In the coaching literature, matching is described as the attempt to identify and pair a coach who is aligned with his or her coachee needs (Wycherley \& Cox, 2008). However, few empirical studies have directly examined the possible predictors of a good coach-coachee match (e.g., Boyce et al., 2010; Bozer, Joo \& Santora, 2015; de Haan et al., 2016; Toegel \& Nicholson, 2005). The studies in our review examine coach-coachee actual and perceived similarity (also referred as commonality) as an antecedent to coaching outcomes. Specifically, same gender coaching dyads were positively related to affective coaching outcomes as reflected in coachee increased self-awareness (Bozer et al., 2015), and skill-based outcomes as reflected in greater improvement in coachees' multisource ratings (Toegel \& Nicholson, 2005). Additionally, coach-coachee perceived similarity based on attitudes, values, and beliefs as rated by the coach was positively related to skill-based 
outcomes as reflected in greater improvement in coachees' supervisory rated task performance (Bozer et al., 2015). In contrast, Boyce et al. found no significant differences between dyads when matched on commonality in personal characteristics or experiences, compatibility in behavioural preferences, and coach credibility scores compared to randomly assigned dyads in affective and skill-based outcomes as measured by satisfaction with the coaching program and leadership performance. De Haan et al. (2016) found no significant relationship between perceived coaching effectiveness and personality matching of coachcoachee. The inconsistency of evidence in relation to this domain is reflected in the lower ratings of quality shown in Table 2 .

Given the non-definitive and limited findings on the impact of matching based on coachcoachee similarity on coaching outcomes, coupled with the lack of agreement in the literature on the matching criteria to be used (Peterson, 2010), future research is needed to clarify whether and how actual or perceived differences or similarities in coach-coachee dyads account for coaching relationship and impact on coaching outcomes. Further, the case can be made for a curvilinear relationship between coach-coachee similarity and coaching effectiveness. That is, that dyad similarity has a positive additive effect on coaching in the initial stages of the coaching relationship (e.g., in the contracting and data collection/analysis steps) as coachees may experience increased levels of interpersonal comfort and engagement. However, as the coaching intervention progresses to subsequent stages (e.g., development and implementation of action plans and progress monitoring), similarity between coach and coachee may have decreased importance or actually lead to a reduction in the quality of coaching relationship, potentially hindering or even decreasing coaching outcomes. In the subsequent stages of coaching, where coachees are required to question their assumptions and experiment with new behaviours, coachees may benefit from having dissimilar coaches who 
are perhaps in a better position to challenge their coachees, engage and support them in getting out of their comfort zone and offer them an alternative perspective. Therefore, studies with a more nuanced approach that separates perceived coach-coachee similarity into discrete, operationally definable criteria are warranted. We suggest that the need for a more nuanced approach to future research in this domain is further warranted given the inconsistency of findings despite the high level of theoretical underpinning to research studies in this area and the relatively high directness of outcome (see Table 2), suggesting that other important factors are yet to be identified.

Future research should also examine how coach-coachee similarity in other characteristics, such as cultural background and goal orientation, are related to coaching outcomes and the importance of these factors through the various stages of the coaching intervention. As with our recommendations for research methodologies in exploring trust, we suggest that an appropriate methodology for understanding the influence of interpersonal attraction on behaviours during the coaching conversation is observational studies. Particularly, to monitor the potential curvilinear relationship between interpersonal attraction and coaching outcomes, multiple observations should be conducted across different stages of the coaching intervention. Whilst further research is required in this category, we suggest that interpersonal attraction research is a medium priority when considered in the context of the other categories explored in our review.

Feedback intervention.

Utilizing behavioural feedback to aid professional development and improve employee performance has become a popular organizational practice (DeNisi \& Kluger, 2000). The 
opportunity for gaining an understanding of how one is perceived by others in the organizational context is seen as important to leadership and managerial effectiveness (e.g., Atwater, Ostroff, Yammarino, \& Fleenor, 1998; Goleman, 1998). Research has supported feedback receptivity, acceptance, and response to feedback as essential facets of feedback effectiveness that are dependent upon the feedback recipient's characteristics, the nature of the message delivered, and feedback source characteristics (e.g., Ilgen, Fisher, \& Taylor, 1979). Despite the popularity of feedback intervention as a development practice, evidence on feedback effects are relatively weak and inconsistent (e.g., Kluger \& DeNisi, 1996; Smither, London, \& Reilly, 2005).

There is general agreement regarding the central role that feedback processes play in coaching (e.g., Joo, 2005; Kochanowski et al., 2010; Sonesh et al., 2015). A coach most often uses multi-source feedback data to gain insight and a comprehensive understanding into the coachee and his or her organization. The coach's feedback information is aimed at enhancing the coachees' awareness of how his or her behaviour affects others, and assisting the coachee in setting specific behavioural objectives and developing a personal development plan (Feldman \& Lankau, 2005). Consequently, several studies in our review conceptualized and examined feedback as a mechanism of effective coaching. Specifically, coach credibility as a feedback source characteristic was found as an antecedent of coaching effectiveness (Bozer et al., 2014). The prevailing literature tends to emphasize the role of the coach as a feedback source and communicator however underestimates the role of the coachee as a feedback recipient. For example, a coachees' receptivity to feedback was found to be a moderator of coaching outcomes (Bozer et al., 2013). We recommend further investigation into the coachees' process skills (e.g., active listening, reflection) that are essential for feedback effectiveness, in order to recognize the contribution that both coach and coachee bring to the 
feedback process. Observational studies may be suitable for this purpose, enabling researchers to explore the coaching rhetoric and identify both coach and coachees' skills that facilitate or hinder effective feedback in the context of coaching.

Research also indicates that other follow-up activities that support and compliment the feedback process can enhance the benefits of the feedback intervention (e.g., Walker \& Smither, 1999; Yukl \& Lepsinger, 1995). This premise forms the theoretical underpinning for several studies in our review that examined feedback data as an outcome of effective coaching. These studies posited coaching as a follow-up facilitation intervention to multisource feedback for learning and development (Gegner, 1997; Goff, Guthrie, Goldring \& Bickman, 2014; Kochnowski et al., 2010; Luthans \& Peterson, 2003; Nieminen et al., 2013; Smither, London, Flautt, Vargas \& Kucine, 2003; Thach, 2002; Toegel \& Nicholson, 2005). In these cases, it was suggested that a coach plays a pivotal role as a feedback facilitator who performs proactive influence tactics (Yukl, Seifert, \& Chavez, 2008), offering the coachee (the recipient of feedback) assessment, challenge, reflection, and support (e.g., Toegel \& Nicholson, 2005). Specifically, the coach assists the coachee in processing and interpreting feedback, raising awareness, taking responsibility for change, challenging assumptions and gaining a new perspective, setting inspiring personal development goals, and staying accountable for actions to achieve goals despite discomfort and setbacks (e.g., Nieminen et al., 2013).

Future research should test at which stage incorporating feedback into coaching is most impactful. We suggest that feedback is often utilized at the start of a coaching intervention, however are there benefits in incorporating feedback through all of the coaching stages? Also, is the feedback direction (either positive or negative feedback) important, for example, does 
incorporating positive feedback from others have a positive impact on coaching outcomes whilst incorporating negative feedback has a negative impact? What is the interaction between feedback in coaching and coachee goal orientation, for example, is feedback only beneficial for those coachees with a learning goal orientation rather than a performance goal orientation? Finally, given the relatively low quality rating for research in this domain (see Table 2) primarily due to the indirectness of intervention, further research should seek to provide direct data on the incremental benefit of feedback in coaching by comparing coaching only with coaching plus feedback intervention conditions. These questions are particularly urgent given that the recent meta-analysis by Jones et al. (2016) found a significantly smaller effect size of coaching on generalized outcomes when coaching was provided in conjunction with multi-source feedback compared to coaching alone. Therefore, we suggest that a focused, theory-informed exploration of the conditions under which feedback plus coaching has a beneficial impact on coaching outcomes is an urgent priority.

\section{Supervisory support}

Research findings have consistently confirmed the positive impact of supervisor support on variables such as pre-training motivation and skills transfer (Awoniyi, Griego, \& Morgan, 2002; Facteau, Dobbins, Russell, Ladd \& Kudisch, 1995; Gumuseli \& Ergin, 2002; van der Klink, Gielen, \& Nauta, 2001). For example, trainees who reported high levels of perceived workplace support experienced better training transfer compared to trainees with low levels of workplace support (e.g., Burke \& Hutchins, 2008; Kontoghiorghes, 2004). As several researchers have argued (Baldwin \& Ford, 1988; House, 1986; Lim, 2001), supervisory variables impose a critical influence on personal outcomes and on the likelihood of successful skills transfer. Lim (2001) noted that among the many people-related organizational climate 
factors for transfer, three factors appeared to influence transfer more than others: discussion with a supervisor about implementing new learning, positive feedback from the supervisor, and the supervisor's involvement in or familiarization with the training process.

Within the coaching literature, Baron and Morin $(2009,2010)$ found positive associations between supervisory support as perceived by the coachee and coach-coachee working alliance. Further, they found working alliance as a mediator of work-environment support (as measured by organizational openness to change, supervisor and peer support) and affective coaching outcomes as reflected by increased coachees' self-efficacy. Baron and Morin (2009, 2010) suggested that the support of the supervisor might reinforce the perceived value of the coaching process and therefore encourage the coachees' efforts to develop. In support of this, Smither et al. (2003) found that employees that participated in coaching were more likely to solicit ideas on how to improve their multisource feedback ratings and achieved improved performance as rated by their direct reports and supervisors. Similarly, Ladegard (2011) found that coachee insight was related to increased social support, which was associated with reduced stress. Ladegard (2011) proposed that increased insight into own strengths and weaknesses may make individuals better able to utilize social resources in their daily work, which contributes to better stress management. Qualitative studies in our review also highlight the importance of supervisory support from the coachees' (Bush, 2004; Hill, 2010), coaches' (Kappenberg, 2008), and HR professionals' perspective (Salomaa, 2015).

Future research should understand exactly what types of supervisory support behaviours are important to encourage learning and performance outcomes from coaching. For example, is the frequency and timing of these behaviours in relation to the coaching process important and how important are supervisory support behaviours in relation to other environmental 
factors? Our review also identified that the coaching literature is theory-light in respect of supervisory support, which is reflected in the relatively low overall quality in this domain (see Table 2). In the training literature, leader-member exchange (LMX) is one theory that has been proposed as an explanation for understanding the influence of leader interactions on training transfer. LMX posits that through different types of exchanges, leaders differentiate the way they treat their followers (Dansereau, Graen \& Haga, 1975) leading to different quality relationships between the leader and each follower (Martin, Guillaume, Thomas, Lee \& Epitropaki, 2016). In the context of training effectiveness and transfer of training, Scaduto, Lindsay and Chiaburu (2008) propose that a broad focus on exchanges with the leader is important for creating more inclusive models off training effectiveness. We argue that this detailed understanding of the LMX is equally as important to understand factors determining coaching effectiveness. Our review found that, to-date, no researchers have directly explored LMX in the context of coaching effectiveness.

We suggest that LMX is an important direction for future research to further understand the influence of supervisory support on coaching effectiveness. Following the recommendations provided by Martin et al. (2016) for future investigation of LMX, we suggest that crosslagged panel designs would be a suitable research methodology in order to help detect changes in both LMX quality across the duration of the coaching intervention and beyond. We classify future research into supervisory support on coaching effectiveness, and in particular, LMX, as a high priority given then scarcity of current research in this area. Adopting a theoretical underpinning such as LMX in this domain would enhance the quality of theory for studies here. Further, by utilizing outcomes from third party or objective sources and ensuring the directness of the coaching intervention would provide greater confidence in relation to the important of supervisory support in ensuring coaching effectiveness. 


\section{Conclusion}

In this paper, we set out to achieve two goals. Firstly, to examine critically the theoretical constructs operationalized in past coaching research to provide a deeper understanding of why these factors are important in understanding what determines coaching effectiveness and secondly, to identify and discuss fundamental questions to be answered and appropriate research methodologies that can advance workplace coaching research and practice.

Our SLR identified a total of 117 studies that matched our inclusion criteria and focused exclusively on formal one-to-one coaching by coach practitioners in an organizational setting. Our review focused around a critical discussion of seven of the most frequently operationalized constructs that are proposed as determining the effectiveness of workplace coaching: self-efficacy, coaching motivation, goal orientation, trust, interpersonal attraction, feedback intervention, and supervisory support. Whilst a number of the theoretical constructs explored in our paper are shared with the training literature, we argue that the key for future research, is to progress towards an understanding of the interaction between these constructs in the coaching context. Gaining a greater understanding of the unique contribution of coaching to learning and performance compared to other interventions such as training or mentoring will advance theory and practice in workplace coaching. For example, the majority of the theoretical constructs discussed in our paper have been explored in isolation, therefore we know very little in relation to the unique exploratory power in explaining coaching effectiveness or whether there is some redundancy in the coverage of each of these theoretical constructs. Furthermore, whilst some of the constructs discussed (such as self-efficacy and goal orientation) benefit from voluminous literature in the wider training context, other constructs explored in our review such as trust and interpersonal attraction are generally 
absent within a normal training context. As these constructs have only been explored in isolation, we are yet to determine how these constructs interact and develop over the course of a coaching intervention. We propose that in order to understand the unique contribution of coaching to learning and performance outcomes, the most promising avenues for future research will be to examine these interactions in detail.

To guide this future research, we formulated a series of research directions for scholars, and highlighted the priority of the area as a whole for future research. Based on the knowledge gaps highlighted in our synthesis, we also made a number of suggestions in relation to necessary advances in terms of the research methodology currently utilized in coaching research. We summarise the suggestions for future research, including suggested methodologies made throughout our paper in Table 3.

Insert Table 3 about here

Additionally, we have two generalised suggestions in relation to future research that we propose are an urgent priority. Firstly, our review has identified that the impact of the theoretical constructs on coaching outcomes varies dependent on the criterion measured. This is supported by the meta-analytic finding of Jones et al. (2016) that showed different effect sizes for the various outcomes in their framework of workplace coaching outcomes. Future research should examine the unique impact of the theoretical constructs explored here at the different outcome levels. Further theorising is also needed in order to understand why the different theoretical constructs interact at the different outcome levels in this way. Secondly, the definition of coaching utilized here specifies that coaching is a reflective, goal-focused relationship (Smither, 2011). Given the fundamental importance of reflection and goal-setting 
in coaching, it is noteworthy that we were unable to include a discussion of these theoretical concepts in our paper. This is because no studies identified in our review directly examined the influence of either reflection or goal-setting in relation to coaching outcomes. We suggest that this is a significant gap in the literature that urgently needs addressing.

We also acknowledge that our strict boundary conditions (i.e., inclusion/exclusion criteria) may be a double-edged sword, as there may have been studies that were excluded from our review due to incomplete reporting of the coaching intervention and context (e.g., goals, approach taken or procedure). Our recommendation is therefore that a more thorough reporting of the coaching intervention in coaching research can increase the scope of future SLRs and, ultimately, achieve a more effective integration of coaching literature. A further potential limitation of our study relates to the seven theoretical constructs explored. During the coding stage of our SLR, we adopted an inductive approach and both authors independently identified the most frequently operationalized theoretical constructs and reached agreement upon which to include in our review. As can be seen in the appendix (available online), there are other theoretical constructs operationalized in the primary studies identified in our review that we have not been able to explore in detail here, for example working alliance. Through our inductive analysis of the primary studies in our review, we believe that we have been able to focus on the seven key theoretical constructs, however as further primary studies are conducted that explore some of the other theoretical constructs, future SLR's may turn to focus on these additional constructs.

We are confident that our paper can make a meaningful contribution to workplace coaching theory and research. We have mapped out the theoretical constructs operationalized in the coaching literature and summarised the findings from these studies. We have further extended 
this contribution by explicitly linking the evidence from the coaching literature to the wider psychological theory and research in a way that the current body of coaching research fails to do. This is particularly important as our review takes a significant step towards understanding the important theoretical constructs that explain the factors that determine workplace coaching effectiveness. Furthermore, our paper has provided specific, theory and research informed recommendations for future research that could significantly progress the field of workplace coaching theory and practice.

\section{References}

Studies marked with a $*$ are included in our systematic review.

Adams, R. J., Smart, P., \& Sigismund Huff, A. (2016). Shades of Grey: Guidelines for Working with the Grey Literature in Systematic Reviews for Management and Organizational Studies. International Journal of Management Reviews, 00, 1-23. doi: 10.1111/ijmr.12102

*Alvey, S., \& Barclay, K. (2007). The characteristics of dyadic trust in executive coaching. Journal of Leadership Studies, 1(1), 18-27. doi:10.1002/j1s.20004

*Ammentorp, J., Jensen, H. I., \& Uhrenfeldt, L. (2013). Danish health professionals' experiences of being coached: A pilot study. Journal of Continuing Education in the Health Professions, 33, 41-47. doi: 10.1002/chp.21157

Armstrong, S. J., Allinson, C. W., \& Hayes, J. (2002). Formal Mentoring Systems: An Examination of the Effects of Mentor/Protégé Cognitive Styles on the Mentoring Process. Journal of Management Studies, 39(8), 1111-1137. doi: 10.1111/1467-6486.00326 
Arvai, J., Campbell-Arvai, V. \& Steel, P. (2012). Decision-making for sustainability: a systematic review of the body of knowledge. Available at: http://nbs.net/knowledge (accessed 2 November 2017).

Atwater, L. E., Ostroff, C., Yammarino, F. J., \& Fleenor, J. W. (1998). Self-other agreement: Does it really matter? Personnel Psychology, 51(3), 577-598. doi: 10.1111/j.17446570.1998.tb00252.x

*Audet , J., \& Couteret, P. (2012). Coaching the entrepreneur: Features and success factors. Journal of Small Business and Enterprise Development, 19(3), 515-531. doi:

$10.1108 / 14626001211250207$

Awoniyi, E. A., Griego, O. V., \& Morgan, G. A. (2002). Person-environment fit and transfer of training. International Journal of Training and Development, 6(1), 25-35. doi: 10.1111/14682419.00147

Baldwin, T. T., \& Ford, J. K. (1988). Transfer of training: A review and directions for future research. Personnel Psychology, 41(1), 63-103. doi: 10.1111/j.1744-6570.1988.tb00632.x

Bandura, A. (1977). Self-efficacy: Toward a unifying theory of behavioral change. Psychological Review, 84(2), 191-215. doi: 10.1037/0033-295X.84.2.191

Bandura, A. (1982). Self-efficacy mechanism in human agency. American Psychologist, 37(2), 122147. doi: 10.1037/0003-066X.37.2.122 
Bandura, A. (1986). Social foundations of thought and action: A social cognitive theory. Upper Saddle River, NJ: Prentice-Hall, Inc.

*Baron, L., \& Morin, L. (2009). The coach-coachee relationship in executive coaching: A field study. Human Resource Development Quarterly, 20(1), 85-106. doi: 10.1002/hrdq.20009

*Baron, L., \& Morin, L. (2010). The impact of executive coaching on self-efficacy related to management soft-skills. Leadership \& Organization Development Journal, 31(1), 18-38. doi: $10.1108 / 01437731011010362$

*Baron, L., Morin, L., \& Morin, D. (2011). Executive coaching: The effect of working alliance discrepancy on the development of coachees' self-efficacy. Journal of Management Development, 30(9), 847-864. doi: 10.1108/02621711111164330

*Bell, S. E. (2005). Myers-Briggs type indicator and executive coaching: Participants' self perceptions about the effectiveness of the two when used together. Doctor of Philosophy, Capella University, Minneapolis, Minnesota.

Bell, B. S., \& Kozlowski, W. J. (2002). Goal orientation and ability: Interactive effects on selfefficacy, performance, and knowledge. Journal of Applied Psychology, 87(3), 497-505. doi: $10.1037 / 0021-9010.87 .3 .497$

*Blackman, A. (2006). Factors that contribute to the effectiveness of business coaching: The coachees perspective. The Business Review, Cambridge, 5(1), 98-104. 
Blackman, A., Moscardo, G., \& Gray, D. E. (2016). Challenges for the theory and practice of business coaching: A systematic review of empirical evidence. Human Resource Development Review, 15(4), 459-486. doi:10.1177/1534484316673177

Blau, P. (1964). Exchange and power in social life. New York: Wiley

*Blazar, D., \& Kraft, M. A. (2015). Exploring mechanisms of effective teacher coaching: A tale of two cohorts from a randomized experiment. Educational Evaluation and Policy Analysis, 37(4), 542-566. doi: 10.3102/0162373715579487

Bono, J. E., Purvanova, R. K., Towler, A. J., \& Peterson, D. B. (2009). A survey of executive coaching practices. Personnel Psychology, 62(2), 361-404. doi: 10.1111/j.17446570.2009.01142.x

Bowen, F., Newenham-Kahindi, A. \& Herremans, I. (2010). When suits meet roots: the antecedents and consequences of community engagement strategy. Journal of Business Ethics, 95, 297318. doi: 10.1007/s10551-009-0360-1

*Bowles, S., Cunningham, C. J. L., De La Rosa, G. M., \& Picano, J. (2007). Coaching leaders in middle and executive management: Goals, performance, buy-in. Leadership \& Organization Development, 28(5), 388-408. doi: 10.1108/01437730710761715 
*Boyce, L. A., Jackson, J. R., \& Neal, L. J. (2010). Building successful leadership coaching relationships: Examining impact of matching criteria in a leadership coaching program. Journal of Management Development, 29(10), 914-931. doi: 10.1108/02621711011084231

*Boysen-Rotelli, S. M. (2013). Executive coaching effectiveness: A quantitative study. Doctor of Philosophy, Benedictine University, Chicago, Illinois.

*Bozer, G., Joo, B.-K., \& Santora, J. C. (2015). Executive coaching: Does coach-coachee matching based on similarity really matter? Consulting Psychology: Practice \& Research, 67(3), 218233. doi: $10.1037 / \mathrm{cpb} 0000044$

*Bozer, G., Sarros, J. C., \& Santora, J. C. (2013). The role of coachee characteristics in executive coaching for effective sustainability. Journal of Management Development, 32(3), 277-294. doi: $10.1108 / 02621711311318319$

*Bozer, G., Sarros, J. C., \& Santora, J. C. (2014). Academic background and credibility in executive coaching effectiveness Personnel Review, 43(6), 881-897. doi: 10.1108/PR-10-2013-0171

Brett, J. F., \& VandeWalle, D. (1999). Goal orientation and goal content as predictors of performance in a training program. Journal of Applied Psychology, 84(6), 863-873. doi: 10.1037/00219010.84 .6 .863

*Bright, D., \& Crockett, A. (2012). Training combined with coaching can make a significant difference in job performance and satisfaction. Coaching: An International Journal of Theory, Research and Practice, 5(1), 4-21. doi: 10.1080/17521882.2011.648332 
Briner, R. B., \& Denyer, D. (2012). Systematic review and evidence synthesis as a practice and scholarship tool In D. M. Rousseau (Ed.), The Oxford Handbook of Evidence-Based Management. New York, NY: Oxford University Press.

Briner, R.B., Denyer, D. and Rousseau, D.M. (2009). Evidence-based management: concept cleanup time? Academy of Management Perspectives, 23(4), 19-32.

*Burke, D., \& Linley, A. P. (2007). Enhancing goal self-concordance through coaching. International Coaching Psychology Review, 2(1), 62-69.

Burke, L. A., \& Hutchins, H. M. (2008). A study of best practices in training transfer and proposed model of transfer. Human Resource Development Quarterly, 19(2), 107-128. doi: 10.1002/hrdq. 1230

Button, S. B., Mathieu, J. E., \& Zajac, D. (1996). Goal orientation in organizational research: A conceptual and empirical foundation. Organizational Behavior and Human Decision Processes 67(1), 26-48. doi: 10.1006/obhd.1996.0063

*Bush, M. W. (2004). Client perceptions of effectiveness in executive coaching. PhD. Doctoral dissertation, Pepperdine University, Malibu.

Byrne, D. (1997). An overview (and underview) of research and theory within the attraction paradigm. Journal of Social and Personal Relationships, 14(3), 417-431. doi: $10.1177 / 0265407597143008$ 
*Carter, A., Blackman, A., \& Hicks, B., Williams, M., \& Hay R. (2017). Perspectives on effective coaching by those who have been coached. International Journal of Training and Development, 21(2), 73-91. doi: 10.1111/ijtd.12098

*Cerni, T., Curtis, G. J., \& Colmar, S. H. (2010). Executive coaching can enhance transformational leadership. International Coaching Psychology Review, 5(1), 81-85.

Choi, J. N., Price, R. H., \& Vinokur, A. D. (2003). Self-efficacy changes in groups: Effects of diversity, leadership, and group climate. Journal of Organizational Behaviour, 24(4), 357372. doi: 10.1002/job.195

Clarke, G. N. (2003). Improving the transition from basic efficacy research to effectiveness studies: Methodological issues and procedures. In A. E. Kazdin (Ed ,..Methodological Issues \& Strategies in Clinical Research 3) ed., pp. 569-587). Washington, DC: American Psychological Association.

Colquitt, J. A., LePine, J. A., \& Noe, R. A. (2000). Toward an integrative theory of training motivation: A meta-analytic path analysis of 20 years of research. Journal of Applied Psychology, 85(5), 678-707. doi: 10.1037//0021-9010.85.5.678

Colquitt, J. A., \& Simmering, M. J. (1998). Conscientiousness, goal orientation, and motivation to learn during the learning process: A longitudinal study. Journal of Applied Psychology, 83, 4, 654-665. doi: 10.1037/0021-9010.83.4.654 
Cooper, H. (2003). Editorial. Psychological Bulletin 129(1), 3-9. doi: 10.1037/0033-2909.129.1.3

*Cortvriend, P., Harris, C., \& Alexander, E. (2008). Evaluating the links between leadership development coaching and performance. International Coaching Psychology Review, 3(2), 164-179.

Cunningham, J. B., \& MacGregor, J. (2000). Trust and the design of work complementary constructs in satisfaction and performance. Human Relations, 53(12), 1575-1591.doi: $10.1177 / 00187267005312003$

Dahling, J. J., Taylor, S. R., Chau, S. L., \& Dwight, S. A. (2016). Does coaching matter? A multilevel model linking managerial coaching skill and frequency to sales goal attainment. Personnel Psychology, 69(4), 863-894. doi:10.1111/peps.12123

Dansereau, F., Graen, G.B., \& Haga, W. (1975). A vertical dyad linkage approach to leadership in formal organizations. Organizational Behavior and Human Performance, 13, 46-78. doi: $10.1016 / 0030-5073(75) 90005-7$

*Dawdy, G. N. (2004). Executive coaching: A comparative design exploring the perceived effectiveness of coaching and methods. Doctor of Philosophy, Capella University, Minneapolis, Minnesota.

*Day, A., De Haan, E., Silis, C., Bertie, C., \& Blass, E. (2008). Coaches' experience of critical moments in the coaching. International Coaching Psychology Review, 3(3), 207-218. 
Day, D. V. (2000). Leadership development: A review in context. Leadership Quarterly, 11(4), 581613. doi: 10.1016/S1048-9843(00)00061-8

*de Figueiredo, M. N., Rodolph, B., Bylund, C. L., Goelz, T., Heußner, P., Sattel, H., .. Wuensch, A. (2015). ComOn coaching: Study protocol of a randomized controlled trial to assess the effect of a varied number of coaching sessions on transfer into clinical practice following communication skills training. BMC Cancer, 15, 1-9. doi: 10.1186/s12885-015-1454-z

*de Haan, E., Bertie, C., Day, A., \& Silis, C. (2010). Clients' critical moments of coaching: Toward a “client model" of executive coaching. Academy of Management Learning \& Education, 9(4), 607-621.

*de Haan, E., Culpin, V., \& Curd, J. (2011). Executive coaching in practice: What determines helpfulness for clients of coaching? Personnel Review, 40(1), 24-44. doi: $10.1108 / 00483481111095500$

*de Haan, E., Duckworth, A., Birch, D., \& Jones, C. (2013). Executive coaching outcome research: The predictive value of common factors such as relationship, personality match and selfefficacy. Consulting Psychology Journal: Practice and Research, 65(1), 40-57. doi: $10.1037 / \mathrm{a} 0031635$

*de Haan, E., Grant, A. M., Burger, Y., \& Eriksson, P.-O. (2016). A large-scale study of executive and workplace coaching: The relative contributions of relationship, personality match, and self-efficacy. Consulting Psychology Journal: Practice and Research, 68(3), 189-207. doi:10.1037/cpb0000058 
De Meuse, K. P., Dai, G., \& Lee, R. J. (2009). Evaluating the effectiveness of executive coaching: Beyond ROI?, Coaching: An International Journal of Theory, Research and Practice, 2(2), 117-134. doi: 10.1080/17521880902882413

*DeFrank-Cole, L., Latimer, M., Reed, M., \& Wheatly, M. (2014). The women's leadership initiative: One university's attempt to empower females on campus. Journal of Leadership, Accountability and Ethics, 11(1), 50-63.

DeNisi, A. S., \& Kluger, A. N. (2000). Feedback effectiveness: Can 360-degree appraisals be improved? Academy of Management Executive, 14(1), 129-139. doi:

10.5465/AME.2000.2909845

Denyer, D., \& Tranfield, D. (2009). Producing a systematic review. In D. A. Buchanan \& A. Bryman (Eds.), The SAGE handbook of organizational research methods (pp. 671-689). London: SAGE Publications.

*Dingman, M. E. (2004). The effects of executive coaching on job-related attitudes. Doctoral Dissertation. Regent University. Virginia, USA

Dirks, K. T. (2000). Trust in leadership and team performance: evidence from NCAA basketball. Journal of Applied Psychology, 85, 6, 1004-1012. doi: 10.1037/00219010.85.6.1004 
Dirks, K. T., \& Ferrin, D. L. (2000). The effects of trust in leadership on employee performance, behavior and attitudes: A meta-analysis. In Academy of Management Proceedings, 2000, 1, 11. doi:10.5465/APBPP.2000.5535181

Doorewaard, H., \& Meihuizen, H. E. (2000). Strategic performance options in professional service organisations. Human Resource Management Journal, 10(2), 39-57. doi: 10.1111/j.17488583.2000.tb00019.x

*Duijts, S. F. A., Kant, I., van den Brandt, P. A., \& Swaen, G. M. H. (2008). Effectiveness of a preventive coaching intervention for employees at risk for sickness absence due to psychosocial health complaints: results of a randomized controlled trial. Occupational and Environmental Medicine, 50(7), 765-776. doi:10.1097/JOM.0b013e3181651584

Dweck, C. S. (1986). Motivational processes affecting learning. American Psychologist, 41(10), 1040. doi: 10.1037/0003-066X.41.10.1040

Dweck, C. S., \& Leggett, E. L. (1988). A social-cognitive approach to motivation and personality. Psychological Review, 95(2), 256. doi: 10.1037/0033-295X.95.2.256

Eby, L. T. D. T., Allen, T. D., Hoffman, B. J., Baranik, L. E., Sauer, J. B., Baldwin, S., \& Evans, S. C. (2013). An interdisciplinary meta-analysis of the potential antecedents, correlates, and consequences of protégé perceptions of mentoring. Psychological Bulletin, 139(2), 441-476. doi: $10.1037 / \mathrm{a} 0029279$. 
Elliot, A. J., \& McGregor, H. A. (2001). A $2 \times 2$ achievement goal framework. Journal of Personality and Social Psychology, 80(3), 501-519. doi: 10.1037/0022-3514.80.3.501

Ely, K., Boyce, L. A., Nelson, J. K., Zaccaro, S. J., Hernez-Broome, G., \& Whymand, W. (2010). Evaluating leadership coaching: A review and integrated framework. The Leadership Quarterly, 21(4), 585-599. doi:10.1016/j.leaqua.2010.06.003

Ennis, S. A., Otto, J., Goodman, R., \& Stern, L. R. (2012). The executive coaching handbook: Principles and guidelines for a successful coaching partnership (5 ed.). Wellesley: MA: The Executive Coaching Forum.

Erdem, F., \& Aytemur, J. Ö. (2008). Mentoring - A relationship based on trust: Qualitative research. Public Personnel Management, 37(1), 55-65. doi: 10.1177/009102600803700104

*Evers, W. J. G., Brouwers, A., \& Tomic, W. (2006). A quasi-experimental study on management coaching effectiveness. Consulting Psychology Journal, 58(3), 174-182. doi: 10.1037/10659293.58.3.174

Facteau, J. D., Dobbins, G. H., Russell, J. E. A., Ladd, R. T. \& Kudisch, J. D. (1995). The influence of general perceptions of the training environment on pretraining motivation and perceived training transfer. Journal of Management, 21, 1-25. doi:10.1177/014920639502100101

*Feggetter, A. J. W. (2007). A preliminary evaluation of executive coaching: Does executive coaching work for candidates on a high potential development scheme? International Coaching Psychology Review, 2(2), 129-142. 
Feldman, D. C., \& Lankau, M. J. (2005). Executive coaching: A review and agenda for future research. Journal of Management 31(6), 829-848. doi: 10.1177/0149206305279599

*Fielden, S. L., Davidson, M. J., \& Sutherland, V. J. (2009). Innovations in coaching and mentoring: Implications for nurse leadership development. Health Services Management Research, 22(2), 92-99. doi: 10.1258/hsmr.2008.008021

*Finn, F. A., Mason, C. M., \& Bradley, L. M. (2007). Doing well with executive coaching: Psychological and behavioral impacts. Paper presented at the Academy of Management Annual Meeting Proceedings, Philadelphia, United States.

Fisher, S. L., \& Ford, J. K. (1998). Differential effects of learner effort and goal orientation on two learning outcomes. Personnel Psychology, 51(2), 397-420. doi: 10.1111/j.17446570.1998.tb00731.x

*Fischer, R. L., \& Beimers, D. (2009). "Put me in, coach": A pilot evaluation of executive coaching in the nonprofit sector. Nonprofit Management \& Leadership, 19(4), 507-522. doi: $10.1002 / \mathrm{nml} .234$

Gallwey, W. T. (2002). The inner game of work: Overcoming mental obstacles for maximum performance. London: Texere. 
*Gan, G. C. G., \& Chong, C. W. (2015). Coaching relationship in executive coaching: A Malaysian study. Journal of Management Development, 34(4), 476-492. doi: 10.1108/JMD-08-20130104

*Gardiner, M., Kearns, H., \& Tiggemann, M. (2013). Effectiveness of cognitive behavioural coaching in improving the well-being and retention of rural general practitioners. Australian Journal of Rural Health, 21(3), 183-189. doi: 10.1111/ajr.12033

*Gatling, A. R., Castelli, P. A., \& Cole, M. L. (2013). Authentic leadership: The role of selfawareness in promoting coaching effectiveness. Asia-Pacific Journal of Management Research and Innovation, 9(4), 337-347. doi: 10.1177/2319510X14523097

*Gegner, C. (1997). Coaching: Theory and practice. Management. Unpublished master's thesis. University of California. San Francisco.

Gist, M. E., \& Mitchell, T. R. (1992). Self-efficacy: A theoretical analysis of its determinants and malleability. The Academy of Management Review. Academy of Management Review, 17(2), 183-211. doi: 10.5465/AMR.1992.4279530

*Goff, P. J., Guthrie, E., Goldring, E., \& Bickman, L. (2014). Changing principals' leadership through feedback and coaching. Journal of Educational Administration, 52(5), 682-704. doi: 10.1108/JEA-10-2013-0113

Goleman, D. (1998). The emotional intelligence of leaders. Leader to Leader, 10(1), 20-26. doi: 10.1002/lt1.40619981008 
Gough, D. (2007). Weight of evidence: a framework for the appraisal of the quality and relevance of evidence. Research Papers in Education, 22(2), 213-228. doi:10.1080/02671520701296189

*Grant, A. M. (2014). The efficacy of executive coaching in times of organisational change. Journal of Change Management, 14(2), 258-280. doi: 10.1080/14697017.2013.805159

*Grant, A. M., Curtayne, L., \& Burton, G. (2009). Executive coaching enhances goal attainment, resilience and workplace well-being: A randomised controlled study. The Journal of Positive Psychology, 4(5), 396-407. doi: 10.1080/17439760902992456

*Grant, A. M., Green, L. S., \& Rynsaardt, J. (2010). Developmental coaching for high school teachers: Executive coaching goes to school. Consulting Psychology Journal: Practice and Research, 62(3), 151-168. doi: 10.1037/a0019212

Grant, A. M., Passmore, J., Cavanagh, M. J., \& Parker, H. (2010). The state of play in coaching today: A comprehensive review of the field. In G. P. Hodgkinson \& K. J. Ford (Eds.), International Review of Industrial and Organizational Psychology, (Vol. 25, pp. 125-168). West Sussex, UK: Wiley-Blackwell.

*Grant, A. M., Studholme, I., Verma, R., Kirkwood, L., Paton, B., \& O’Connor, S. (2017). The impact of leadership coaching in an Australian healthcare setting. Journal of Health Organization and Management, 31(2), 237-252. doi:10.1108/JHOM-09-2016-0187 
*Gray, D. E., Ekinci, Y., \& Goregaokar, H. (2011). Coaching SME managers: business development or personal therapy? A mixed methods study. The International Journal of Human Resource Management, 22(4), 863-882. doi: 10.1080/09585192.2011.555129

Gumuseli, A. I., \& Ergin, B. (2002). The manager's role in enhancing the transfer of training: A Turkish case study. International Journal of Training and Development, 6(2), 80-97. doi: $10.1111 / 1468-2419.00151$

Guyatt, G. H., Oxman, A. D., Kunz, R., Woodcock, J., Brozek, J., Helfand, M., . . Schünemann, H. J. (2011a). GRADE guidelines: 8. Rating the quality of evidence-indirectness. Journal of Clinical Epidemiology, 64(12), 1303-1310. doi:10.1016/j.jclinepi.2011.04.014

Guyatt, G. H., Oxman, A. D., Kunz, R., Woodcock, J., Brozek, J., Helfand, M., . . Schünemann, H. J. (2011b). GRADE guidelines: 7. Rating the quality of evidence-inconsistency. Journal of Clinical Epidemiology, 64(12), 1294-1302. doi:10.1016/j.jclinepi.2011.03.017

Guyatt, G. H., Oxman, A. D., Vist, G. E., Kunz, R., Falck-Ytter, Y., Alonso-Coello, P., \& Schünemann, H. J. (2008). GRADE: An emerging consensus on rating quality of evidence and strength of recommendations. BMJ, 336, 924-926. doi:10.1136/bmj.39489.470347.AD

*Gyllensten, K., \& Palmer, S. (2005a). Can coaching reduce workplace stress? A quasi-experimental study. International Journal of Evidence Based Coaching and Mentoring, 3(2), 75-85. 
*Gyllensten, K., \& Palmer, S. (2005b). The relationship between coaching and workplace stress: A correlational study. International Journal of Health Promotion and Education, 43(3), 97-103. doi: $10.1080 / 14635240.2005 .10708048$

*Gyllensten, K., \& Palmer, S. (2006). Experiences of coaching and stress in the workplace: An Interpretative Phenomenological Analysis. International Coaching Psychology Review, 1(1), $86-98$.

*Gyllensten, K., \& Palmer, S. (2007). The coaching relationship: An interpretative phenomenological analysis. International Coaching Psychology Review, 2(2), 168-177.

Harrison, D. A., Price, K. H., \& Bell, M. P. (1998). Beyond relational demography: Time and the effects of surface-and deep-level diversity on work group cohesion. Academy of Management Journal, 41(1), 96-107. doi: 10.2307/256901

Hertenstein, E. J. (2001). Goal orientation and practice condition as predictors of training results. Human Resource Development Quarterly, 12(4), 403-419. doi: 10.1002/hrdq.1005

*Hill, G. (2010). Executive coaching: Perspectives of effectiveness from executives and coaches. Master of Business, Queensland University of Technology, Brisbane.

Hogg, M. A., \& Turner, J. C. (1985). Interpersonal attraction, social identification and psychological group formation. European Journal of Social Psychology, 15(1), 51-66. doi: 10.1002/ejsp.2420150105 
House, R. J. (1986). Leadership training: Some dysfunctional consequences. Administrative Science Quarterly, 12(4), 556-571. doi: 10.2307/2391533

International Coach Federation. (2016). ICF global coaching study. Retrieved from https://coachfederation.org/files/FileDownloads/2016ICFGlobalCoachingStudy_ExecutiveSu mmary.pdf

Ilgen, D. R., Fisher, C. D., \& Taylor, M. S. (1979). Consequences of individual feedback on behavior in organizations. Journal of Applied Psychology, 64(4), 349-371. doi: 10.1037/00219010.64.4.349

*James-Ward, C. (2013). The coaching experience of four novice principals. International Journal of Mentoring and Coaching in Education, 2(1), 21-33. doi: 10.1108/20466851311323069

Janssen, S., van Vuuren, M., \& de Jong, M. D. T. (2015). Informal mentoring at work: A review and suggestions for future research. International Journal of Management Reviews, Advance online publication. doi:10.1111/ijmr.12069

Jones, A. P., James, L. R., \& Bruni, J. R. (1975). Perceived leadership behavior and employee confidence in the leader as moderated by job involvement. Journal of Applied Psychology, 60(1), 146-149. doi: 10.1037/h0076359

*Jones, R. A., Rafferty, A. E., \& Griffin, M. A. (2006). The executive coaching trend: Towards more flexible executives. Leadership \& Organization Development Journal, 27(7), 584-596. doi: $10.1108 / 01437730610692434$ 
*Jones, R. J. (2015). The effectiveness of workplace coaching: A meta-analysis of learning and performance outcomes; scale development; theoretical model of individual differences and longitudinal study. Unpublished Doctoral Dissertation. Aston University. Birmingham, UK.

Jones, R. J., Napiersky, U., Lyubovnikova, J., \& Chretien, O. (2017). What is Team Coaching? Conceptualizing the Distinctiveness of Team Coaching. Unpublished manuscript.

Jones, R. J., Woods, S. A., \& Guillaume, Y. R. F. (2016). The effectiveness of workplace coaching: A meta-analysis of learning and performance outcomes from coaching. Journal of Occupational and Organizational Psychology, 89(2). doi: 10.1111/joop.12119

*Jones, R. J., Woods, S. A., \& Hutchinson, E. (2014). The influence of the Five Factor Model of personality on the perceived effectiveness of executive coaching International Journal of Evidence Based Coaching and Mentoring, 12(2), 109-118.

*Jones, R. J., Woods, S. A., \& Zhou, Y. (2017). Boundary Conditions of Workplace Coaching Outcomes. Unpublished manuscript

Joo, B.-K. (2005). Executive coaching: A conceptual framework from an integrative review of practice and research. Human Resource Development Review, 4(4), 462-488. doi: $10.1177 / 1534484305280866$ 
*Jowett, S., Kanakoglou, K., \& Passmore, J. (2012). The application of the 3+1Cs relationship model in executive coaching. Consulting Psychology Journal: Practice and Research, 64(3), 183197. doi: $10.1037 / \mathrm{a} 0030316$

Judge, T. A., \& Bono, J. E. (2001). Relationship of core self-evaluations traits—self-esteem, generalized self-efficacy, locus of control, and emotional stability—with job satisfaction and job performance: A meta-analysis. Journal of Applied Psychology, 86(1), 80-92. doi: $10.1037 / / 0021-9010.86 .1 .80$

Kafner, R., Ackerman, P. L., Murtha, T. C., Dugdale, B., \& Nelson, L. (1994). Goal setting, conditions of practice, and task performance: A resource allocation perspective. Journal of Applied Psychology, 79(6), 826-835. doi: 10.1037/0021-9010.79.6.826

*Kampa-Kokesch, S. (2001). Executive Coaching as an Individually Tailored Consultation Intervention: Does it Increase Leadership? PhD. Doctoral dissertation, Western Michigan University, Michigan.

*Kappenberg, E. S. (2008). A model of executive coaching: Key factors in coaching success. Doctoral Dissertation. The Claremont Graduate University. California.

Kilburg, R. R. (1996). Toward a conceptual understanding and definition of executive coaching. Consulting Psychology Journal: Practice \& Research, 48(2), 134-144. doi: 10.1037/10614087.48.2.134 
*Kines, P., Andersen, L. P. S., Spangenberg, S., Mikkelsen, K. L., Dyreborg, J., \& Zohar, D. (2010). Improving construction site safety through leader-based verbal safety communication. Journal of Safety Research, 41(5), 399-406. doi: 10.1016/j.jsr.2010.06.005

Kluger, A. N. \& DeNisi, A. (1996). The effects of feedback intentions on performance: A historical review, a meta-analysis, and a preliminary feedback intention theory. Psychological Bulletin, 119(2), 254-284. doi: 10.1037/0033-2909.119.2.254

*Kochanowski, S., Seifert, C. F., \& Yukl, G. A. (2010). Using coaching to enhance the effects of behavioral feedback to managers. Journal of Leadership \& Organizational Studies, 17(4), 363-369. doi: $10.1177 / 1548051809352663$

*Kombarakaran, F. A., Yang, J. A., Baker, M. N., \& Fernandes, P. B. (2008). Executive coaching: It works! Consulting Psychology Journal: Practice and Research, 60(1), 78-90. doi: $10.1037 / 1065-9293.60 .1 .78$

Konovsky, M., \& Pugh, D. (1994). Citizenship behavior and social exchange. Academy of Management Journal, 37(3), 656-669. doi: 10.2307/256704

Kontoghiorghes, C. (2004). Reconceptualizing the learning transfer conceptual framework: Empirical validation of a new systemic model. International Journal of Training and Development, 8(3), 210-221. doi: 10.1111/j.1360-3736.2004.00209.x

Kozlowski, S. W. J., Gully, S. M., Brown, K. G., Salas, E., Smith, E. M., \& Nason, E. R. (2001). Effects of training goals and goal orientation traits on multidimensional training outcomes and 
performance adaptability. Organizational Behavior and Human Decision Processes, 85(1), 131. doi: 10.1006/obhd.2000.2930

*Ladegard, G. (2011). Stress management through workplace coaching: The impact of learning experiences. International Journal of Evidence Based Coaching and Mentoring, 9(1), 29-43.

*Ladegard, G., \& Gjerde, S. (2014). Leadership coaching, leader role-efficacy, and trust in subordinates: A mixed methods study assessing leadership coaching as a leadership development tool. The Leadership Quarterly, 25(4), 631-646. doi:

10.1016/j.leaqua.2014.02.002

*Leonard-Cross, E. (2010). Developmental coaching: Business benefit - fact or fad? An evaluative study to explore the impact of coaching in the workplace. International Coaching Psychology Review, 5(1), 36-47.

*Levenson, A. (2009). Measuring and maximizing the business impact of executive coaching. Consulting Psychology Journal: Practice and Research, 61(2), 103-121. doi:10.1037/a0015438

*Lewis-Duarte, M., \& Bligh, M. C. (2012). Agents of "influence": exploring the usage, timing, and outcomes of executive coaching tactics. Leadership \& Organization Development Journal, 33(3), 255-281. doi: 10.1108/01437731211216461

*Libri, V., \& Kemp, T. (2006). Assessing the efficacy of a cognitive behavioural executive coaching programme. International Coaching Psychology Review, 1(2), 9-18. 
Lim, D. H. (2000). Training design factors influencing transfer of training to the workplace within an international context. Journal of Vocational Education and Training, 52(2), 243-258. doi: 10.1080/13636820000200118

Lim, D. H. (2001). The effect of work experience and job position on international learning transfer. International Journal of Vocational Education and Training, 9(2), 59-74.

*Luthans, F., \& Peterson, S. J. (2003). 360-degree feedback with systematic coaching: Empirical analysis suggests a winning combination. Human Resource Management, 42(3), 243-256. doi: 10.1002/hrm.10083

Lyons, L.,M., \& Perrewé, P.,L. (2014). Examination of the interpersonal predictors of mentoring relational quality. Career Development International, 19(4), 381-403.

*Mackie, D. (2014). The effectiveness of strength-based executive coaching in enhancing full range leadership development: A controlled study. Consulting Psychology Journal: Practice and Research, 66(2), 118-137. doi: 10.1037/cpb0000005

*Mackie, D. (2015a). The effects of coachee readiness and core self-evaluations on leadership coaching outcomes: A controlled trial. Coaching: An International Journal of Theory, Research and Practice, 8(2), 120-136. doi: 10.1080/17521882.2015.1019532 
*Mackie, D. (2015b). Who sees change after leadership coaching? An analysis of impact by rater level and self-other alignment on multi-source feedback. International Coaching Psychology Review, 10(2), 118-130.

Macpherson, A., \& Jones, O. (2010). Editorial: Strategies for the development of international journal of management reviews. International Journal of Management Reviews, 12(2), 107113. doi: $10.1111 /$ j.1468-2370.2010.00282.x

Martin, R., Guillaume, Y., Thomas, G., Lee, A., \& Epitropaki, O. (2016). Leader-member exchange (LMX) and performance: A meta-analytic review. Personnel Psychology, 69, 67-121. doi: 10.1111/peps. 12100

Martocchio, J. J., \& Webster, J. (1992). Effects of feedback and cognitive playfulness on performance in microcomputer software training. Personnel Psychology, 45(3), 553-578. doi: 10.1111/j.1744-6570.1992.tb00860.x

Mayer, R. C., Davis, J. H., \& Schoorman, F. D. (1995). An integrative model of organizational trust. Academy of Management Review, 20(3), 709-734. doi:10.5465/AMR.1995.9508080335

Mayer, R. C., \& Davis, J. H. (1999). The effect of the performance appraisal system on trust for management: A field quasi-experiment. Journal of Applied Psychology, 84(1), 123-136. doi: $10.1037 / 0021-9010.84 .1 .123$

McCauley, C. D., \& Hezlett, S. A. (2002). Individual development in the workplace. In N. Anderson, D. Ones, H. K. Sinangil, \& C. Viswesvaran (Eds.), Handbook of Industrial, Work and 
Organizational Psychology: Personnel Psychology, Vol 1 (pp. 313 - 335). Thousand Oaks, CA: Sage.

*McGuffin, A. A., \& Obonyo, E. (2010). Enhancing performance: A case study of the effects of employee coaching in construction practice. Construction Management and Economics, 28(2), 141-149. doi: 10.1080/01446190903460672

Mitchell, M. E., Eby, L. T., \& Ragins, B. R. (2015). My mentor, myself: Antecedents and outcomes of perceived similarity in mentoring relationships. Journal of Vocational Behavior, 89, 1-9. doi: 10.1016/j.jvb.2015.04.008

*Moen, F., \& Allgood, E. (2009). Coaching and the effect on self-efficacy. Organization Development Journal, 27(4), 69-82.

*Moen, F., \& Federici, R. A. (2012a). The effect from external executive coaching. Coaching: An International Journal of Theory, Research and Practice, 5(2), 113-131. doi: $10.1080 / 17521882.2012 .708355$

*Moen, F., \& Federici, R. A. (2012b). The effect of external executive coaching and coaching-based leadership on need satisfaction. Organization Development Journal, 30(3), 63-74.

*Moen, F., \& Skaalvik, E. (2009). The effect from executive coaching on performance psychology International Journal of Evidence Based Coaching and Mentoring, 7(2), 32-49. 
Moher, D., Liberati, A., Tetzlaff, J., \& Altman, D. G. (2009). Preferred reporting items for systematic reviews and meta-analyses: The PRISMA statement. BMJ, 339. doi:10.1136/bmj.b2535

*Nieminen, L. R. G., Smerek, R., Kotrba, L., \& Denison, D. (2013). What does an executive coaching intervention add beyond facilitated multisource feedback? Effects on leader selfratings and perceived effectiveness. Human Resource Development Quarterly, 24(2), 145176. doi: $10.1002 /$ hrdq. 21152

Nolan, C. T., \& Garavan, T. N. (2016). Human resource development in SMEs: A systematic review of the literature. International Journal of Management Reviews, 18(1), 85-107. doi: 10.1111/ijmr.12062

Nutley, S., Powell, A. and Davies, H. (2013). What counts as good evidence? Provocation paper for the alliance for useful evidence. Available at: http://www.alliance4 usefulevidence.org (accessed 1 November 2016).

*O'Connor, S., \& Cavanagh, M. (2013). The coaching ripple effect: The effects of developmental coaching on wellbeing across organisational networks. Psychology of Well-Being: Theory, Research and Practice, 3(2), 1-23. doi: 10.1186/2211-1522-3-2

*Olivero, G., Bane, K. D., \& Kopelman, R. E. (1997). Executive coaching as a transfer of training tool: Effects on productivity in a public agency. Public Personnel Management, 26(4), 461469. doi: $10.1177 / 009102609702600403$ 
*Orenstein, R. L. (2006). Measuring executive coaching efficacy? The answer was right here all the time. Consulting Psychology Journal: Practice \& Research, 58(2), 106-116. doi: 10.1037/1065-9293.58.2.106

*Paige, H. (2002). Examining the effectiveness of executive coaching on executives. International Education Journal, 3(2), 61-70.

Pajares, F. (1996). Self-efficacy beliefs in academic settings. Review of Educational Research, 66(4), 543-578. doi: 10.3102/00346543066004543

*Parker-Wilkins, V. (2006). Business impact of executive coaching: demonstrating monetary value. Industrial and Commercial Training, 38(3), 122-127. doi: 10.1108/00197850610659373

Passmore, J., \& Fillery-Travis, A. (2011). A critical review of executive coaching research: A decade of progress and what's to come. Coaching: An International Journal of Theory, Research and Practice, 4(2), 70-88. doi: 10.1080/17521882.2011.596484

Payne, S. C., Youngcourt, S. S. \& Beubien, J. M. (2007). A meta-analytic evaluation of the goal orientation nomological net. Journal of Applied Psychology, 92(1), 128-150. doi: 10.1037/0021-9010.92.1.128

*Perkins, R. D. (2009). How executive coaching can change leader behavior and improve meeting effectiveness: An exploratory study. Consulting Psychology Journal: Practice and Research, 61(4), 298-318. doi: 10.1037/a0017842 
*Peterson, D. B. (1993). Measuring change: A psychometric approach to evaluating individual coaching outcomes. Paper presented at the Annual Conference of The Society for Industrial and Organizational Psychology, San Francisco, California.

Peterson, D. B. (2010). Executive coaching: A critical review and recommendations for advancing the practice. In S. Zedeck (Ed.), American psychological association handbook of industrial and organizational psychology: Selecting and developing members for the organization (Vol. 2, pp. 527-566). Washington, DC: American Psychological Association.

Peterson, D. B., \& Hicks, M. D. (1996). Leader as coach: Strategies for coaching and developing others. Minneapolis, MN: Personnel Decisions International.

Quiñones, M. A. (1995). Pretraining context effects: Training assignment as feedback. Journal of Applied Psychology, 80(2), 226-238. doi: 10.1037/0021-9010.80.2.226

*Rappe, C., \& Zwick, T. (2007). Developing leadership competence of production unit managers. Journal of Management Development, 26(4), 312-330. doi: 10.1108/02621710710740084

*Ratiu, L., David, O. A., \& Baban, A. (2015). Developing managerial skills through coaching: Efficacy of a cognitive-behavioral coaching program. Journal of Rational-Emotive \& Cognitive-Behavior Therapy. 1-23. doi: 10.1007/s10942-015-0225-8

Rees, T., Hardy, L., Arne, G., Bruce, A., Côté, J., Woodman , T., . . Warr, C. (2016). The Great British medalists project: A review of current knowledge on the development of the world's best sporting talent. Sports Medicine, 46(8), 1041-1058. doi:10.1007/s40279-016-0476-2 
*Rekalde, I., Landeta, J., \& Albizu, E. (2015). Determining factors in the effectiveness of executive coaching as a management development tool. Management Decision, 53(8), 1677-1697. doi: 10.1108/MD-12-2014-0666

Rousseau, D. M., Sitkin, S. B., Burt, R. S., \& Camerer, C. (1998). Not so different after all: A crossdiscipline view of trust. Academy of Management Review, 23(3), 393-404. doi: 10.5465/AMR.1998.926617

Salas, E., \& Cannon-Bowers, J. A. (2001). The science of training: A decade of progress. Annual Review of Psychology, 52(1), 471-499. doi: 10.1146/annurev.psych.52.1.471

*Saling, N. E. (2005). An Empirical study comparing the effect of feedback, training, and executive coaching on leadership behavior change. Doctoral dissertation. North Carolina State University.

*Salomaa, R. (2015). Expatriate coaching: Factors impacting coaching success. Journal of Global Mobility, 3(3), 216-243. doi: 10.1108/JGM-10-2014-0050

Scaduto, A., Lindsay, D., \& Chiaburu, D. S. (2008). Leader influences on training effectiveness: motivation and outcome expectation processes. International Journal of Training and Development, 12, 158-170. doi: 10.1111/j.1468-2419.2008.00303.x 
Schwarzer, R. (1994). Optimism, vulnerability, and self-beliefs as health-related cognitions: A systematic overview. Psychology and Health, 9(3), 161-180. doi:10.1080/08870449408407475

Schwarzer, R., \& Fuchs, R. (1995). Self-efficacy and health behaviours (pp.163-196). In M. Conner, \& P. Norman. (Eds.). Predicting Health Behaviour: Research and Practice with Social Cognition Models. (pp. 163-196). Buckingham: Open University Press.

*Scriffignano, R. S. (2011). Coaching within organisations: Examining the influence of goal orientation on leaders' professional development. Coaching: An International Journal of Theory, Research and Practice, 4(1), 20-31. doi: 10.1080/17521882.2010.550898

*Seebe, I., Scheiner, C. W., \& Voigt, K.-I. (2011). Coaching Liberal Professionals in the Start-up Phase: What Influences its Effectiveness? Paper presented at the ICSB World Conference Proceedings, Stockholm, Sweden.

Shelton, S. H. (1990). Developing the construct of general self-efficacy. Psychological Reports, 66 (3), 987-994

*Smith, I. M., \& Brummel, B. J. (2013). Investigating the role of the active ingredients in executive coaching. Coaching: An International Journal of Theory, Research and Practice, 6(1), 57-71. doi: 10.1080/17521882.2012.758649 
Smither, J. W. (2011). Can psychotherapy research serve as a guide for research about executive coaching? An agenda for the next decade. Journal of Business and Psychology, 26(2), 135145. doi: 10.1007/s10869-011-9216-7

*Smither, J. W., London, M., Flautt, R., Vargas, Y., \& Kucine, I. (2003). Can working with an executive coach improve multisource feedback ratings over time? A quasi-experimental field study. Personnel Psychology, 56(1), 23-44. doi: 10.1111/j.1744-6570.2003.tb00142.x

Smither, J. W., London, M., \& Reilly, R. R. (2005). Does performance improve following multisource feedback? A theoretical model, meta-analysis, and a review of empirical findings. Personnel Psychology, 58(1), 33-66.doi: 10.1111/j.1744-6570.2005.514_1.x

*Sonesh, S. C., Coultas, C. W., Marlow, S. L., Lacerenza, C. N., Reyes, D., \& Salas, E. (2015). Coaching in the wild: Identifying factors that lead to success. Consulting Psychology Journal: Practice and Research, 67(3), 189-217. doi: 10.1037/cpb0000042

*Spurk, D., Kauffeld, S., Barthauer, L., \& Heinemann, N. S. R. (2015). Fostering networking behavior, career planning and optimism, and subjective career success: An intervention study. Journal of Vocational Behaviour, 87, 134-144. doi:10.1016/j.jvb.2014.12.007

Stajkovic, A. D., \& Luthans, F. (1998). Social cognitive theory and self-efficacy: Going beyond the traditional motivational and behavioral approaches. Organizational Dynamics, 26(4), 62-74. doi: 10.1016/S0090-2616(98)90006-7 
*Stewart, L. J., Palmer, S., Wilkin, H., \& Kerrin , M. (2008). The influence of character: does personality impact coaching success? International Journal of Evidence Based Coaching and Mentoring, 6(1), 32-42.

*Styhre, A. (2008). Coaching as second-order observations: Learning from site managers in the construction industry. Leadership \& Organization Development Journal, 29(3), 275-290. doi: $10.1108 / 01437730810861326$

*Styhre, A., \& Josephson, P. E. (2007). Coaching the site manager: Effects on learning and managerial practice. Construction Management and Economics, 25(12), 1295-1304. doi: $10.1080 / 01446190701466111$

*Sun, B. J., Deane, F., Crowe, T., Andresen, R., \& Oades, L. G. (2013). A preliminary exploration of the working alliance and 'real relationship' in two coaching approaches with mental health workers. International Coaching Psychology Review, 8(2), 6-17.

*Swart, J., \& Harcup, J. (2013). 'If I learn do we learn?': The link between executive coaching and organizational learning. Management Learning, 44(4), 337-354. doi: $10.1177 / 1350507612447916$

*Taie, E. S. (2011). Coaching as an approach to enhance performance. Journal for Quality and Participation, 34(1), 34-38.

Tannenbaum, S. I., Mathieu, J. E., Salas, E., \& Cannon-Bowers, J. A. (1991). Meeting trainees' expectations: The influence of training fulfillment on the development of commitment, self- 
efficacy, and motivation. Journal of Applied Psychology, 76(6), 759-769. doi: 10.1037/00219010.76.6.759

*Teemant, A. (2014). A mixed-methods investigation of instructional coaching for teachers of diverse learners. Urban Education, 49(5), 574-604. doi: 10.1177/0042085913481362

*Thach, E. C. (2002). The impact of executive coaching and 360-feedback on leadership effectiveness. Leadership \& Organization Development Journal, 23(4), 205-214. doi: $10.1108 / 01437730210429070$

Theeboom, T., Beersma, B., \& Van Vianen, A. E. M. (2014). Does coaching work? A meta-analysis on the effects of coaching on individual level outcomes in an organizational context. The Journal of Positive Psychology, 9(1), 1-18. doi: 10.1080/17439760.2013.837499

Thomas, J., \& Harden, A. (2008). Methods for the thematic synthesis of qualitative research in systematic reviews. BMC Medical Research Methodology, 8(1), 45. doi:10.1186/1471-2288$8-45$

Tims, M., Bakker, A, B., \& Derks, D. (2014). Daily job crafting and the self-efficacy-performance relationship. Journal of Managerial Psychology, 29(5), 490-507. doi: 10.1108/JMP-05-20120148

*Toegel, G., \& Nicholson, N. (2005). Multisource feedback, coaching, and leadership development: Gender homophily in coaching dyads. Paper presented at the Academy of Management Annual Conference, Honolulu, Hawaii. 
*Tooth, J.-A., Nielsen, S., \& Armstrong, H. (2013). Coaching effectiveness survey instruments: taking stock of measuring the immeasurable. Coaching: An International Journal of Theory, Research and Practice, 6(2), 137-151. doi: 10.1080/17521882.2013.802365

*Trathen, S. A. (2007). Executive coaching, changes in leadership competencies and learning agility amongst Microsoft senior executives. PhD Dissertation. School of Education. Colorado State University. Fort Collins, Colorado.

Tsui, A. S., \& O'Reilly, C. A. (1989). Beyond Simple Demographic Effects: The Importance of Relational Demography in Superior-Subordinate Dyads. The Academy of Management Journal, 32(2), 402-423. doi: 10.2307/256368

van der Klink, M., Gielen, E. \& Nauta, C. (2001). Supervisory support as a major condition to enhance transfer. International Journal of Training and Development, 5, 52-63. doi: $10.1111 / 1468-2419.00121$

VandeWalle, D. (1997). Development and validation of a work domain goal orientation instrument. Educational and Psychological Measurement, 57(6), 995-1015. doi: 10.1177/0013164497057006009

VandeWalle, D., \& Cummings, L. L. (1997). A test of the influence of goal orientation on the feedback-seeking process. Journal of Applied Psychology, 82(3), 390-400. doi: 10.1037/00219010.82 .3 .390 
*Van Hove, L. (2015). Does executive coaching really develop management skills? An experimental study among executives. Paper presented at the Academy of Management Proceedings, Vancouver, Canada.

*Van Oosten, E. B. (2013). The impact of emotional intelligence and executive coaching on leader effectiveness. Doctoral Dissertation. Case Western Reserve University. Cleveland, Ohio.

Varela, O. E., Cater, J. J., \& Michel, N. (2011). Similarity attraction in learning contexts: An empirical study. Human Resource Development Quarterly, 22(1), 49-68. doi: 10.1002/hrdq.20066

*Vidal-Salazar, M. a. D., Ferro'n-Vı'lchez, V., \& Cordo'n-Pozo , E. (2012). Coaching: An effective practice for business competitiveness. Competitiveness Review: An International Business Journal, 22(5), 423-433. doi: 10.1108/10595421211266302

*Wales, S. (2003). Why coaching? Journal of Change Management, 3(3), 275-282. doi: $10.1080 / 714042542$

Walker, A. G., \& Smither, J. W. (1999). A five-year study of upward feedback: what managers do with their results matters. Personnel Psychology, 52(2), 393-423. doi: 10.1111/j.17446570.1999.tb00166.x

*Walston, S. L. (2014). Chief executive officers' perceived value of coaching: Individual and organisational influences. Coaching: An International Journal of Theory, Research and Practice, 7(2), 115-131. doi: 10.1080/17521882.2014.924543 
Wang, C. L., \& Chugh, H. (2014). Entrepreneurial learning: Past research and future challenges. International Journal of Management Reviews, 16(1), 24-61. doi: DOI: 10.1111/ijmr.12007

Wang, S., Tomlinson, E. C., \& Noe, R. A. (2010). The role of mentor trust and protege internal locus of control in formal mentoring relationships. Journal of Applied Psychology, 95(2), 358-367. doi: $10.1037 / \mathrm{a} 0017663$

Webb, P. J. (2006). Back on track: The coaching journey in executive career derailment. International Coaching Psychology Review, 1(2), 68-74.

Whitener, E., Brodt, S., Korsgaard, M. A., \& Werner, J. (1998). Managers as initiators of trust: An exchange relationship for understanding managerial trustworthy behavior. Academy of Management Journal, 23(3), 513-530. doi:10.5465/AMR.1998.926624

Whitmore, J. (2002). Coaching for performance. London: Nicholas Brealey.

*Williams, J. S. (2016). An investigation of goal-focused and process-oriented approaches to executive coaching using random assignment and switching replications designs. $\mathrm{PhD}$ Dissertation, Alliant International University, California.

Witherspoon, R., \& White, R. P. (1996). Executive coaching: A continuum of roles. Consulting psychology Journal: Practice and Research, 48(2), 124-133. doi: 10.1037/10614087.48.2.124 
Wolf, F. M. (1986). Meta-analysis: Quantitative methods for research synthesis. Beverly Hills, CA: Sage.

Wycherley, I. M., \& Cox, E. (2008). Factors in the selection and matching of executive coaches in organisations. Coaching: An International Journal of Theory, Research and Practice, 1(1), 39-53. doi: 10.1080/17521880701878075

Xanthopoulou, D., Bakker, A. B., Demerouti, E., \& Schaufeli, W. B. (2009). Work engagement and financial returns: A diary study on the role of job and personal resources. Journal of Occupational and Organizational Psychology, 82(1), 183-200. doi:10.1348/096317908X285633

Xanthopoulou, D., Bakker, A. B., Heuven, E., Demerouti, E., \& Schaufeli, W. B. (2008). Working in the sky: A diary study on work engagement among flight attendants. Journal of Occupational Health Psychology, 13(4), 345-356. doi:10.1037/1076-8998.13.4.345

*Yedreshteyn, S. (2008). A Qualitative investigation of the implementation of an internal executive coaching program in a global corporation, grounded in organizational psychology theory. Doctor of Psychology, Rutgers, New Jersey, NJ.

*Yu, N., Collins, C. G., Cavanagh, M., White, K., \& Fairbrother, G. (2008). Positive coaching with frontline managers: Enhancing their effectiveness and understanding why. International Coaching Psychology Review, 3(2), 110-122. 
Yukl, G., \& Lepsinger, R. (1995). How to get the most out of 360 degree feedback. Training, 32(12), 45-50.

Yukl, G., Seifert, C. F., \& Chavez, C. (2008). Validation of the extended influence behavior questionnaire. The Leadership Quarterly, 19(5), 609-621. doi: 10.1016/j.leaqua.2008.07.006 
Table 1. Summary of coaching outcomes measured split by theoretical construct

\section{Outcome}

\begin{tabular}{lcccc} 
Construct & Affective & Cognitive & Skill-based & Results \\
\hline Self-efficacy & 23 & 4 & 9 & 3 \\
Coaching motivation & 15 & 2 & 6 & 2 \\
Goal orientation & 4 & 2 & 3 \\
Trust & 13 & 8 & \\
Interpersonal attraction & 3 & &
\end{tabular}

Note: Some studies measured multiple outcomes across different categories 
Table 2. Overview of assessment of quality for each of the seven theoretical constructs

\begin{tabular}{|l|c|c|c|c|c|}
\hline Theme & $\begin{array}{c}\text { Design quality } \\
\text { (explicit } \\
\text { theoretical } \\
\text { underpinning) }\end{array}$ & $\begin{array}{c}\text { Consistency } \\
\text { of evidence }\end{array}$ & $\begin{array}{c}\text { Directness of } \\
\text { outcome }\end{array}$ & $\begin{array}{c}\text { Directness } \\
\text { of } \\
\text { intervention }\end{array}$ & $\begin{array}{c}\text { Overall } \\
\text { assessment } \\
\text { of quality }\end{array}$ \\
\hline Self-efficacy & 0.92 & 1 & 0.56 & 0.71 & 0.80 \\
\hline
\end{tabular}

The evidence to indicate the presence of self-efficacy as both a predictor and outcome of coaching is relatively robust with consistent evidence across the studies in our review.

However, there is only a moderate level of confidence in relation to directness of outcome as the majority of outcomes are self-reported at the coachee level rather than from third-party or objective sources.

\begin{tabular}{|l|l|l|l|l|l|}
\hline $\begin{array}{l}\text { Coaching } \\
\text { motivation }\end{array}$ & 0.76 & 1 & 0.59 & 0.82 & 0.79 \\
\hline
\end{tabular}

The evidence suggests that coaching motivation is an important antecedent of coaching outcomes with studies in our review yielding consistent results. However, as with selfefficacy, there is only a moderate level of confidence in relation to directness of outcome as the majority of outcomes are self-reported at the coachee level rather than from third-party or objective sources.

\begin{tabular}{|l|c|c|c|c|c|}
\hline $\begin{array}{l}\text { Goal } \\
\text { orientation }\end{array}$ & 1 & 1 & 0.75 & 0.75 & .88 \\
\hline
\end{tabular}

There is strong evidence to indicate that coachee goal orientation is relevant to understanding coaching outcomes. This variable has been investigated using primarily quantitative research designs with a greater number of studies utilizing outcomes measured by third-party or objective sources.

\begin{tabular}{|l|c|c|c|c|c|}
\hline Trust & 0.54 & 1 & 0.46 & 0.92 & 0.73 \\
\hline Whilst
\end{tabular}

Whilst the evidence consistently indicates that trust in the coaching relationship is important across studies exploring this construct, the overall quality of studies is moderate due to the reliance on surrogate outcomes (i.e. coaches ratings) and a paucity of theoretical underpinning in these studies.

\begin{tabular}{|l|c|c|c|c|c|}
\hline $\begin{array}{l}\text { Interpersonal } \\
\text { attraction }\end{array}$ & 1 & 0 & .75 & 0.75 & 0.63 \\
\hline
\end{tabular}

The findings regarding the importance of interpersonal attraction are relatively inconsistent, however the quality of theoretical underpinning of studies exploring this variable is high and there are also a greater number of studies utilizing outcomes measured by third-party or objective sources.

\begin{tabular}{|l|l|l|l|l|l|}
\hline $\begin{array}{l}\text { Feedback } \\
\text { intervention }\end{array}$ & 0.71 & 0 & 0.79 & 0.43 & 0.48 \\
\hline
\end{tabular}


The overall quality of studies exploring the importance of feedback intervention in coaching is relatively low. This is partially attributable to the low directness of intervention, as frequently when feedback intervention is investigated with coaching, the two interventions are combined, without a comparison group. On the other hand, this theme does included a relatively high number of studies utilizing outcomes measured by third-party or objective sources.

\begin{tabular}{|l|c|c|c|c|c|}
\hline $\begin{array}{l}\text { Supervisory } \\
\text { support }\end{array}$ & 0.75 & 0 & 0.44 & 0.63 & 0.46 \\
\hline
\end{tabular}

The overall quality of studies exploring the importance of supervisory support in coaching is relatively low. This is primarily due to the inconsistency in findings across studies, the reliance on self-report measures of outcomes and the high number of studies in this group with a low level of directness of intervention.

Note: For study design and consistency, a score of 1 indicates on average most studies within this theme included an explicit underpinning theoretical framework and demonstrate high levels of homogeneity in findings. A score of 0 indicates on average most studies within this theme do not include an explicit underpinning theoretical framework and demonstrate high levels of heterogeneity in findings. For directness of outcomes, a rating of 1.0 indicates high directness evidenced by outcomes gathered from objective measures or third-parties, a rating of 0.5 indicates moderate directness evidenced by self-reported (coachee) outcomes, and a rating of 0.0 indicates low directness evidenced by outcomes gathered from 'surrogate' (coach) outcomes. For directness of intervention, a rating of 1 indicates high directness evidenced by an isolated one-to-one coaching intervention whereas a rating of 0 indicates low directness evidenced by one-to-one coaching combined with another intervention. Study design and directness are mean scores calculated from the ratings provided for individual studies shown in the supplementary info table in the appendix available online. The overall assessment of quality is the mean of the other scores provided here and is provided on a scale from 0.0 to 1.0 . 
Table 3. Summary of recommend future research directions and suggested research methodology

\begin{tabular}{ll}
\hline Research question & Research methodology \\
\hline Self-efficacy &
\end{tabular}

What is the relative influence of global self-efficacy beliefs

Diary studies compared to domain-specific self-efficacy and task-specific self-efficacy on coaching effectiveness?

\section{Coaching motivation}

Is coaching motivation an affective outcome of workplace coaching?

\section{Goal orientation}

Is learning goal orientation an affective outcome of workplace coaching?

Longitudinal design

Trust

What characteristics are more likely to lead to the coachee developing strong perception of trust in their coach?

Once trust is established, what is the impact on participant behaviours during coaching conversations?

Longitudinal design

\section{Interpersonal attraction}

What is the relative importance of actual and perceived Observational studies coach-coachee similarity/differences on coaching outcomes throughout different stages of the coaching intervention?

Is there a curvilinear relationship between coach-coachee similarity and coaching outcomes?

Experimental design

Observational studies

\section{Feedback intervention theory}

At which stage is incorporating feedback into coaching most impactful?

What is the comparative impact of utilizing positive versus negative feedback in coaching?

Supervisory support

What types of supervisory support behaviours are important to encourage learning and performance outcomes from coaching (i.e. frequency, timing)?

Experimental design

Experimental design

Longitudinal design 


\begin{tabular}{ll}
\hline Research question & Research methodology \\
\hline $\begin{array}{l}\text { What is the impact of leader-member exchange on coaching } \\
\text { effectiveness and does leader-member exchange quality }\end{array}$ & Cross-lagged panel designs \\
improve over the duration of the coaching intervention? & \\
Interaction of theoretical constructs & \\
What is the unique contribution of coachee self-efficacy, & Longitudinal design \\
coaching motivation and goal orientation on coaching & \\
effectiveness? & \\
What is the nature of the interaction between trust in the & Experimental design \\
coaching relationship, coaching motivation and interpersonal & \\
attraction? & \\
$\begin{array}{l}\text { Does a high level of trust in the coaching relationship lead to } \\
\text { increased coachee self-efficacy through a mediating role of }\end{array}$ & Experimental design \\
feedback receptivity? & \\
$\begin{array}{l}\text { What is the interaction between feedback in coaching and } \\
\text { coachee goal orientation? }\end{array}$ & Experimental design
\end{tabular}

